February 14, 1995

\title{
Consequences of Kinetic Dispersion on the Electrochemistry of an Adsorbed Redox-Active Monolayer
}

Gary K. Rowe, Michael T. Carter, John N. Richardson, Royce W. Murray*

Kenan Laboratories of Chemistry, Univ. of North Carolina, Chapel Hill, NC 27599-3290

\begin{abstract}
Mixed monolayers of (ferrocenylcarboxy)-alkanethiol/ $n$-alkanethiol have been investigated electrochemically in $2: 1(\mathrm{v}: \mathrm{v})$ chloroethane:butyronitrile solvent in the temperature range of $120 \mathrm{~K}$ to $150 \mathrm{~K}$. Cyclic voltammetry of these monolayers shows large oxidation-reduction peak potential separations indicative of electron transfer rate control. The voltammetric waveshapes are also broadened; this and curved log[i] vs. time transients observed in potential step experiments are interpreted as a dispersion in the reaction rates of the ferrocene sites. This paper considers origins and three models for such kinetic dispersion: (i) Using simulations, the observed kinetic dispersion effects can be successfully represented by a Gaussian distribution among the formal potentials $\mathrm{E}^{0}$, of the surface redox sites. While only an apparent kinetic dispersion (having a thermodynamic origin), we show by simulations that its presence affects potential step $\log \left[\mathrm{k}_{\mathrm{APP}, \eta}\right] v s . \eta$ plots, depressing the apparent reorganizational barrier energies $(\lambda)$ and elevating the apparent rate constants $\left(k^{0}\right)$, consistent with previous experimental observations. Similarly, cyclic voltammetric simulations with a Gaussian $\mathrm{E}^{0}$ distribution give excellent fits to experimental
\end{abstract}


voltammograms with mid-point average rates (that with voltammograms can be simulated to fit both the experimental waveshape and $\Delta \mathrm{E}_{\mathrm{PEAK}}$ ) that are roughly 6-fold smaller than the average rate (determined from a fit to the experimental $\Delta \mathrm{E}_{\mathrm{PEAK}}$ assuming a homogeneous population). The temperature and chain length dependence of simulations are also consistent with experimental observations and indicate that the dispersion has little effect on accurate determination of $\lambda$ (from an activation analysis) or $\beta$ (from a plot of $\log \left(\mathrm{k}^{0}\right) v s$. chain length). (ii) A Gaussian distribution of reorganizational energies, which is a real kinetic dispersion, has consequences on the appearance and the analysis of data quantitatively equivalent to those of a distribution of formal potentials. (iii) A kinetic dispersion model based on a Gaussian distribution of tunneling distances (or equivalently electronic coupling parameter) from the electrode surface is also evaluated. This model predicts curved potential step $\log [\mathrm{i}] v s$. time plots, and in analysis of $\log \left[\mathrm{k}_{\mathrm{APP}, \eta}\right] v s . \eta$ plots, undistorted results for $\lambda$ but alteration of the apparent $\mathbf{k}^{0}$. 


\section{INTRODUCTION}

The extraordinary order of electroactive self-assembled alkanethiol monolayers (SAMs) chemisorbed on gold has provoked intense interest ${ }^{1-27}$ in using them to study effects of distance, order, and chemical environment on heterogeneous electron-transfer events. Among the kinetic investigations of these systems, those of Chidsey ${ }^{1}$ and Finklea ${ }^{2}$ stand out. Both groups interpreted $\log \left[\mathrm{k}_{\mathrm{APP}}\right] v s$. over-potential $(\eta)$ plots with the $\mathrm{Marcus}^{28}$ free energyrate relation, obtained rate constants $\left(\mathrm{k}^{0}\right)$ and reorganizational energy barriers $(\lambda)$ to electron transfer, and found similar electronic coupling coefficients $\left(\beta=1.02\right.$ to 1.1 per $\left.\mathrm{CH}_{2}\right)$ and symmetrical Tafel plots supporting a through-bond tunneling mechanism. Nearly ideal, kinetically-homogeneous behavior was observed ${ }^{1,29}$ in aqueous acid.

Electroactive SAMs on gold in aqueous electrolyte have been studied over a limited temperature range, and investigations in non-aqueous solvents have encountered monolayer instability. ${ }^{2 c, 6 a, 29}$ This is unfortunate since temperature variation is another route to reorganization barrier determination, and being non-adiabatic, these electron-transfer reactions should depend on dielectric energetics not dynamics. Nonaqueous solvents are more amenable to measurements at lowered temperatures and also may alter monolayer selforganization in insightful ways. Finklea has observed non-ideal cyclic voltammetry and nonlinear potential step $\ln [\mathrm{i}]$ vs. time plots for $\left[\mathrm{Ru}\left(\mathrm{NH}_{3}\right)_{5} \mathrm{Py}\right]^{2+/ 3+}$ monolayers ${ }^{2 c}$, which gave relatively stable responses in several organic solvents. Reorganization energy barriers determined from potential step-derived $\log \left[\mathrm{k}_{\mathrm{APP}}\right] v s . \eta$ plots were slightly lower in less polar solvents, did not correlate well with dielectric continuum theory, and were suggested to be influenced by monolayer disorder. These results are consistent with a dispersion of kinetic 
rates in the organic solvents.

As part of a project on electron-transfer kinetics at superconductor electrodes ${ }^{30}$, we have measured ${ }^{4,31}$ the electron transfer kinetics of ferrocene-terminated SAM's over a $115 \mathrm{~K}$ to $175 \mathrm{~K}$ temperature range in a binary organic cryoelectrochemical solvent. We, as Finklea, ${ }^{2 c}$ also observe non-ideal cyclic voltammetric and potential-step behavior, and have sought to examine the consequences of this kinetic dispersity in the determination of kinetic parameters. (Specifically, the ferrocene-terminated monolayers exhibit broadened cyclic voltammetric waveshapes and curved $\log [i] v s$. time plots in potential step experiments.) We find that the temperature dependance of $\mathrm{k}^{0}$ derived from measured cyclic voltammetric $\Delta \mathrm{E}_{\text {PEAK }}$ values yields reorganization energy barriers $(\lambda)$ and (extrapolated) $k_{273}^{0}$ rate constants that are, for several SAM alkyl chain lengths, reasonably consistent with dielectric continuum theory and the aqueous phase results of Chidsey ${ }^{1 c}$. Analysis of ferrocene SAM voltammetric waveshapes and of potential step $\log \left[\mathrm{k}_{\mathrm{APP}}\right] v s$. over-potential plots, on the other hand, gave much lower results for $\lambda$, and anomalous variations with temperature and potential sweep rate.

Hypothesizing that the latter methods fail, at least in part, because of aspects of kinetic dispersion, we model effects of kinetic dispersion on determinations of rate constants, reorganizational barrier energies, and a distance transmission coefficient. This paper presents calculations based on a Gaussian distribution of formal potentials of the redox sites in the electroactive SAM. The distribution of formal potentials is selected to match the broadened voltammetric waveshape. The thermodynamically-based distribution is shown to lead to an apparent dispersion in electron transfer rate constants, and upon analysis by 
$\log \left[\mathrm{k}_{\mathrm{APP}}\right] v s$. over-potential plots, low values of determined $\lambda$. We also consider a real kinetic dispersion by modeling a Gaussian distribution of electron-transfer tunneling distances, again analyzing its effects on $\log \left[\mathrm{k}_{\mathrm{APP}}\right] v s$. over-potential plots.

\section{EXPERIMENTAL}

Chemicals. $\mathrm{CpFeCpCO}\left(\mathrm{CH}_{2}\right)_{\mathrm{x}}-\mathrm{SH}(\mathrm{Cp}=$ cyclopentadienyl; $\mathrm{x}=8,12,16)$ were prepared by a literature method. ${ }^{1 \mathrm{~b}}$ Octanethiol, dodecanethiol, hexadecanethiol (Aldrich), $\mathrm{HCl}$ (Mallinckrodt), $\mathrm{HNO}_{3}$ (EM Science), butyronitrile (PrCN, Aldrich, 99+\%), absolute ethanol (AAPER Alcohol and Chemical Co.), and tetra-n-butylammonium hexafluorophosphate $\left(\mathrm{Bu}_{4} \mathrm{NPF}_{6}\right.$, Fluka, Puriss grade) were used as received. Ethyl chloride (EtCl, Linde) was condensed into a Schlenk tube and stored at room temperature. Water was purified with a Barnstead NANOpure system.

Electrode Fabrication. Working and pseudo-reference electrodes were prepared by soldering Teflon shrouded silver coated copper wires to the ends of a $2 \mathrm{~mm}$ dia. Ag rod (Johnson Matthey Electronics, $99.999 \%$ ) and $0.5 \mathrm{~mm}$ dia. Au wire, respectively, and encapsulating these side-by-side in a cylinder of insulating epoxy (Shell Epon 828, $m$-phenylenediamine curing agent, cured overnight at $70^{\circ} \mathrm{C}$ ). The cylinder was sanded (Buehler 600 grit) to expose the $\mathrm{Ag}$ and $\mathrm{Au}$ disk surfaces, which before each use were polished with successively finer alumina powder (Buehler) aqueous slurries down to $0.3 \mu \mathrm{m}$ grit and sonicated for five minutes in NANOpure water.

Chemisorbed Monolayer Preparation. The Au electrodes were etched in dilute aqua-regia (3:1:6 $\mathrm{H}_{2} \mathrm{O}, \mathrm{HCl}, \mathrm{HNO}_{3}$ ) for 5 minutes, rinsed with copious water then ethanol, immersed in the coating solution for a minimum of 24 hours, and then rinsed thoroughly with ethanol. 
Ethanolic coating solutions contained of 1:3 mole ratios (1 $\mathrm{m} \underline{\mathrm{M}}$ total concentration) of (ferrocenylcarboxy)-octanethiol and $n$-octanethiol, or (ferrocenylcarboxy)-dodecanethiol and dodecanethiol, or (ferrocenylcarboxy)-hexadecanethiol and hexadecanethiol. Following Chidsey ${ }^{1 \mathrm{~b}}$, co-chemisorption with $n$-alkane thiols has the purpose of reducing ferroceneferrocene interactions and film defect-based lateral ferrocene-ferricenium electron transfers. The Ag pseudo-reference was scraped to expose a fresh metal surface. No incubation of chemisorbed films in diluent solution ${ }^{1 \mathrm{~b}}$ was employed.

Electrochemical Measurements. Because $\mathrm{EtCl}$ (bp 285K) is a gas at room temperature and to avoid possible thiol desorption, subsequent manipulations were conducted at dry ice temperature. The working-reference assembly (vide infra) was rinsed with chilled butyronitrile and fitted into a slotted stainless steel cylinder, the closed Pt-faced end of which served as the counter electrode. The working-counter electrode separation was adjusted to ca. $0.5 \mathrm{~mm}$ to minimize cell resistance. The cell was filled with chilled $2: 1$ (v:v) EtCl:PrCN electrolyte solution $\left(0.075 \underline{\mathrm{M}}\right.$ in $\left.\mathrm{Bu}_{4} \mathrm{NPF}_{6}\right)$ and the three electrode assembly inserted into the electrochemical cell which was then placed into a liquid helium cryostat (Janis Model 6CND-NVT, Lakeshore Model 805 temperature controller) and brought to the desired temperature (in the present study, $120 \mathrm{~K}$ to $150 \mathrm{~K}, \pm 0.5 \mathrm{~K}$ ).

Cyclic voltammetry (CV) and potential step experiments were carried out using a potentiostat of local construction and a microcomputer (Micro Systems Engineering 486) with a home made program for potential control and data acquisition. A home built active filter ${ }^{32}$ was employed to improve $\mathrm{S} / \mathrm{N}$ and a positive feedback control circuit ${ }^{32}$ was employed to effect instrumental positive feedback uncompensated resistance correction. The 
uncompensated resistance correction could be estimated from the setting on the feedback compensation module. Actual uncompensated resistances were measured by AC impedance in each experiment at the temperature of interest with a Schlumberger-Solartron Instruments Model 1255 frequency response analyzer and a Model 1286 potentiostat. The quantity of electroactive chemisorbed ferrocene, $\Gamma_{\mathrm{Fc}}$, was measured from the charge under the ferricenium reduction wave in a slow potential scan $(e . g ., 5-10 \mathrm{mV} / \mathrm{s})$ cyclic voltammogram. Potential steps were initiated from the cyclic voltammetrically-determined surfaceconfined ferrocene $e^{0 /+}$ formal potential, $\mathrm{E}^{0}$, and are thus equal to the applied over-potential, $\eta$. The measured transients were typically $0.2-20$ secs long depending upon the temperature and the size of the potential step. The applied potential was returned to $\mathrm{E}^{0}$, and the film equilibrated for 2-5 min. to re-establish the original ferrocene/ferricenium population before initiation of the next over-potential step.

Background current-time transients were obtained in each experiment by carrying out potential steps of the same magnitude and sign as $\eta$, in the flat, featureless double layer potential regions adjacent to the ferrocene potential region (at potentials well negative of $\mathrm{E}^{0}$ '). Currents shown are thusly background-corrected.

Simulations. All simulated voltammograms and current-time transients were calculated on a 486DX PC with a standard spreadsheet program and/or a home made pascal program ${ }^{4 a}$. Simulated voltammograms and potential step current-time transients for a Gaussian distribution of $\mathrm{E}^{0}$, were generated with 21 separate values (enough so that the results are unchanged for larger numbers of values; at smaller numbers of values this is not so) of voltammetric peak potentials and $\mathrm{E}_{\mathrm{FWHM}}$, and of rate constants as a function of charge 
segment in plots of $\log (\mathrm{i}) v s$. time.

\section{RESULTS AND DISCUSSION}

Cyclic Voltammetric Waveshape Broadening. A typical cyclic voltammogram at $135 \mathrm{~K}$ from our investigation ${ }^{31 a}$ of (ferrocenylcarboxy)dodecanethiol + dodecanethiol mixed monolayers chemisorbed on polycrystalline gold is shown in Figure 1. The oxidation and reduction waves are well-formed and similarly shaped, with an average peak width at half-maximum $\left(\mathrm{E}_{\mathrm{FWHM}}\right)$ of $117 \mathrm{mV}$. The large oxidation-reduction peak separation $\left(\Delta \mathrm{E}_{\mathrm{PEAK}}=310 \mathrm{mV}\right)$ is characteristic of slow electron transfer kinetics of an adsorbed electroactive species. The ferrocene coverage $\Gamma_{\mathrm{Fc}}=1.3 \times 10^{-10} \mathrm{~mol} / \mathrm{cm}^{2}$, is $c a .1 / 3$ of a full monolayer. ${ }^{33}$ The monolayers are exceptionally stable at low temperature, with $\Gamma_{\mathrm{Fc}}$ and voltammetry quantitatively reproducible for as long as a week or more. The monolayers are, however, voltammetrically unstable at room temperature, and desorb quickly. ${ }^{3}$

The Figure 1 voltammetry differs from room temperature aqueous observations ${ }^{1 a, b}$ in that the double layer charging current is larger and the ferrocene waveshape is broadened $\left(E_{\mathrm{FWHM}}\right)$. In aqueous electrolyte, ${ }^{34}$ the double-layer capacitance of n-alkanethiol monolayers on $\mathrm{Au}(111)$ follows simple Helmholtz behavior and for a (ferrocenylcarboxy)dodecanethiol+dodecanethiol monolayer like that in Figure 1 is $^{34} 1.7$ $\mu \mathrm{F} / \mathrm{cm}^{2}$. The double layer capacitance for the monolayer in Figure 1, estimated from voltammetric charging currents at potentials more negative than the ferrocene wave, is 18 $\mu \mathrm{F} / \mathrm{cm}^{2}$ in the $\mathrm{EtCl} / \mathrm{PrCN}$ solvent, over 10-fold larger (Table I). Such increases in doublelayer capacitances in organic solvents have been seen before. ${ }^{6 a, 29,35}$ We infer that the monolayer in Figure 1 has significant permeability to ions and/or solvent, and probably an 
associated level of disorder. The capacitances of (ferrocenylcarboxy)-

octanethiol +octanethiol, (ferrocenylcarboxy)-dodecanethiol + dodecanethiol, and

(ferrocenylcarboxy)-hexadecanethiol +hexadecanethiol monolayers in $\mathrm{EtCl}: \mathrm{PrCN}$ all increase

with increasing temperature (Table I). In fact, the capacitances of the C8 and C12

monolayers are both similar and not much smaller than that for a bare surface, ${ }^{36}$ the double layer capacitance of which also increase with increasing temperature. ${ }^{36}$ The capacitance for these monolayers seems mainly dominated by ionic permeability rather than the absolute thickness of the layer anticipated based on the known structure of similar layers.

$$
\begin{gathered}
i=n F A k_{b} \Gamma_{R}^{*} \exp \left[\left(\frac{R T}{-(1-\alpha) n F}\right)\left(\frac{k_{b}}{v}\right)\right] \\
k_{b}=k_{b}^{0} \exp \left(\frac{(1-\alpha) \eta F}{R T}\right)
\end{gathered}
$$

The more readily analyzed aspect of the Figure 1 voltammogram is its unusually large $\mathrm{E}_{\mathrm{FWH}}$. Calculations show that a waveshape broadening of $117 \mathrm{mV}$ at $135 \mathrm{~K}$ is much greater than expected from the degree of slow electron transfer kinetics indicated by the overpotential $\left(\Delta \mathrm{E}_{\mathrm{PEAK}} / 2\right)$. Calculations using Butler-Volmer kinetics for oxidative surface voltammetry according to Laviron $^{37}$, predict that $\mathrm{E}_{\mathrm{FWHM}}$ should be only $57 \mathrm{mV}$ at $135 \mathrm{~K}$ and $\alpha$ $=0.5$, for any value of $\nu, \mathrm{k}_{\mathrm{b}}, \eta$, and $\Gamma_{\mathrm{R}}{ }^{*}$. Other comparisons of experimental and calculated $\mathrm{E}_{\mathrm{FWHM}}$ are shown in Table I. The $\mathrm{E}_{\mathrm{FWHM}}$ predicted from Equations $1 \mathrm{a}$ and $\mathrm{b}$ shows only a weak dependence on $\mathrm{T}$ (Table I, column headed $\mathrm{E}_{\mathrm{FWHM}}$, BV) or $\alpha$. The experimental $\mathrm{E}_{\mathrm{FWHM}}$ values (Table I) increase at lower temperatures and with increasing chain length. We will discuss these results in more detail later on. 
$\mathrm{E}_{\mathrm{FWHM}}$ for a surface voltammetric wave can also be predicted with the Marcus-DOS kinetic model described by Tender et $\mathrm{al}^{4 \mathrm{a}}$ and Creager and Weber ${ }^{4 \mathrm{~b}}$ for cyclic voltammetry, based on that by Chidsey for potential steps ${ }^{12}$. This model avoids the assumptions of ButlerVolmer theory about the relative values of reaction free energy $(\eta)$ and reorganization energy barrier $(\lambda)$, and accounts for the continuum of electronic states in the metal electrode by integration of the Marcus relation ${ }^{28 a, b}$ over a range of energies about the Fermi level of the metal electrode, i.e. ${ }^{38}$

$$
k_{a x / r e d, \eta}=\mu \rho k_{B} T \int_{-\infty}^{\infty} \frac{\exp \left(-\left(x \pm \frac{\lambda+\eta}{K_{B} T}\right)^{2} \frac{k_{B} T}{4 \lambda}\right)}{1+\exp (x)} d x
$$

The outer sphere $\lambda$ estimated from the dielectric continuum equation ${ }^{28}$

$$
\lambda=\frac{e^{2} N}{8 \pi \epsilon_{0}}\left(\frac{1}{a}-\frac{1}{2 d}\right)\left(\frac{1}{\epsilon_{o p}}-\frac{1}{\epsilon_{s}}\right)
$$

gives $\lambda=0.75 \mathrm{eV}$ at $120 \mathrm{~K}$ and $0.77 \mathrm{eV}$ at $150 \mathrm{~K}^{39}$ in the $\mathrm{EtCl} / \mathrm{PrCN}$ mixed solvent. (These $\lambda$ values are near the result, $0.89 \mathrm{eV}$, of an activation analysis of the (ferrocenylcarboxy)dodecanethiol monolayer rate constant reported elsewhere ${ }^{31 \mathrm{a}}$.) Using $\lambda=0.80 \mathrm{eV}$, and selecting $\mathrm{k}^{0}=1.03 \times 10^{-3} \mathrm{~s}^{-1}$ and $\mu \rho=8.54 \times 10^{5} \mathrm{~s}^{-1} \mathrm{eV}^{-1}$ so that a $10 \mathrm{mV} / \mathrm{s}$ voltammogram calculated from Equation 2 has the same $\Delta \mathrm{E}_{\mathrm{PEAK}}(310 \mathrm{mV})$ as observed in Figure 1, gives a predicted value of $\mathrm{E}_{\mathrm{FWHM}}=70 \mathrm{mV}$ at $135 \mathrm{~K}$. The calculated $\mathrm{E}_{\mathrm{FWHM}}, \mathrm{M}-\mathrm{DOS}$ is, while larger than the $\mathrm{E}_{\mathrm{FWHM}}, \mathrm{BV}$, again more narrow than that of the Figure 1 experiment (as are other comparisons between Equation 2 and experiment, shown in Table I). Thus, the $\mathrm{E}_{\mathrm{FWHM}}$ predicted from both kinetic models (Equations 1,2 ) are significantly smaller than the 
experimental value as long as a single value of rate constant, $\lambda$, or $\mathrm{E}^{0}$ ' is assumed as above. Kinetic Dispersion Modelled in Cyclic Voltammetry as a Distribution of Formal Potentials. The voltammetric waveshape broadening in Figure 1 and non-linear potential step $\ln [\mathrm{i}]$ vs. time plots (vide infra, Figure 4$)^{31}$ appear to reflect a dispersion of the rates at which the ferrocene sites react. There can be several sources of such kinetic dispersion. We consider first a model in which the kinetic dispersion arises from a spread in the formal potentials, $\mathrm{E}^{0}$, of the surface ferrocene sites. Such a spread of thermodynamic potentials could arise from uneven ion-pairing $\left(\mathrm{Fc}^{+}, \mathrm{PF}_{6}^{-}\right)$or ferrocene site-site interactions, or from a distribution of monolayer structures that induce uneven interactions or incur a range of solvation shells. Whatever its source, a spread in $\mathrm{E}^{\mathrm{o}^{\prime}}$ will lead to an apparent spread or dispersion in electron transfer rates and analyzed rate constants, as we show in this section.

Definitive proof of a distribution of formal potentials, to distinguish it from other potential sources of kinetic heterogeneity, could be gleaned from a slow scan rate voltammetric experiment so as to give a reversible response. In the case of an $\mathrm{E}^{0}$, distribution, the reversible voltammetric peak shape should remain broad, but it is difficult at low temperature to scan slowly enough to attain this condition. However, the same films studied here, when examined ${ }^{4 a}$ at room temperature in aqueous electrolyte, are both close to reversibility and still broad. This observation tends to eliminate other possible sources of waveshape broadening such as double layer effects as discussed later. That is, there is a strong possibility that an $\mathrm{E}^{0}$, distribution exists for the monolayer results discussed here.

A kinetic heterogeneity based on a thermodynamic distribution (potentially Gaussian) of energy gaps between ground and excited state levels for donor-acceptor molecules 
undergoing photochemically-induced electron transfer has been discussed by GudowskaNowak ${ }^{40}$ to explain experimentally observed inhomogeneous line broadening and nonexponential decay. This is analogous to an electroactive monolayer with a distribution of $\mathrm{E}^{0}$, and thus non-ideal voltammetry and potential step behavior.

We model a distribution of $\mathrm{E}^{0}$, with a standard Gaussian expression

$$
f(y)=\frac{1}{\sigma\left(E^{0^{\prime}}\right) \sqrt{(}(2 \pi)} \exp -\left[(y-\mu)^{2} / 2\left(\sigma\left(E^{0}\right)\right)^{2}\right]
$$

where $\sigma\left(\mathrm{E}^{0}\right)$ is the standard deviation of the distribution. Voltammetric curves were calculated with the Marcus-DOS Equation 2 to match experimental voltammograms by selecting appropriate values of $\sigma\left(\mathrm{E}^{0}\right)$ and summing a minimum of 21 separate voltammograms with $\mathrm{E}^{0}$, values lying between $\pm 3 \sigma\left(\mathrm{E}^{0}\right)$ and scaled by the Gaussian function. A clarification regarding rate constants determined with Equation 2 from cyclic voltammograms exhibiting a Gaussian distribution of $\mathrm{E}^{0}$, is useful at this point. We consider two kinds of rate constants, the first being the mid-point average rate constant $\mathrm{k}_{\mathrm{MPA}}^{0}$, which is that with which a voltammogram can be simulated using Equation 2 and a Gaussian distribution of $\mathrm{E}^{0}$, to fit both the experimental voltammogram's shape, $\mathrm{E}_{\mathrm{FWHM}}$ and $\Delta \mathrm{E}_{\mathrm{PEAK}}$, and the second is the average rate constant $\mathrm{k}_{\mathrm{AV}}^{0}$, which is the rate constant determined from the best fit of $\Delta \mathrm{E}_{\mathrm{PEAK}}$ values (experimental or simulated) to values predicted by Equation 2 , assuming a homogeneous population of reacting sites. The latter procedure has been employed ${ }^{4,31}$ in our previous assessments of experimental monolayer kinetics, and involves no modelling of the kinetic dispersion.

Figure 2 shows a calculated voltammogram based on the distribution $\sigma\left(\mathrm{E}^{0}\right)=55$ 
$\mathrm{mV}, \mu \rho_{\mathrm{MPA}}=1.48 \times 10^{5} \mathrm{eV}^{-1} \mathrm{~s}^{-1}, \lambda=0.80 \mathrm{eV}, \mathrm{T}=135 \mathrm{~K}$, and the mid-point average rate constant $\mathrm{k}_{\mathrm{MPA}}^{0}=1.78 \times 10^{-4} \mathrm{~s}^{-1}$. The excellent fit to the experimental voltammogram of Figure 1 demonstrates that an $\mathrm{E}^{0}$, distribution is a viable explanation for the observed voltammetric broadening. The minor differences between the two voltammograms in Figure 2 appear to result from the experimental background capacitance current. While it is possible $e^{4,5}$ to fit the experimental waveshapes with Equation 2 without assuming an $\mathrm{E}^{0}$, distribution, this requires the use of values of $\lambda$ much smaller $(0.40 \mathrm{eV})^{4}$ than that predicted by Equation 3 or obtained from an activation plot. ${ }^{31}$

The value of $\mathrm{k}_{\mathrm{AV}}^{0}=1.03 \times 10^{-3} \mathrm{~s}^{-1}$ for a $\Delta \mathrm{E}_{\mathrm{PEAK}}$ (only) best fit to Figure 1 is 5.8 -fold larger than the $\mathrm{k}_{\mathrm{MPA}}^{0}$ determined above $\left(1.78 \times 10^{-4} \mathrm{~s}^{-1}\right)$. Thus, in this example, the inclusion of a Gaussian $\mathrm{E}^{\mathrm{o}}$ ' distribution into the kinetic analysis of experimental data produces a "midpoint average" rate constant $\left(\mathrm{k}_{\mathrm{MPA}}^{0}\right)$ that is 5.8 -fold smaller than an "average" analysis ${ }^{31}$ based on $\Delta \mathrm{E}_{\mathrm{PEAK}}$ values alone $\left(\mathrm{k}_{\mathrm{AV}}^{0}\right)$ and assuming no $\mathrm{E}^{\mathrm{o}}$ ' dispersion at all. We assume that the $\mathrm{E}^{\mathrm{o}}$ of the "mid-point average" ferrocene site in the Gaussian distribution is equal to the true $\mathrm{E}^{0}$, (i.e., for no dispersion, and where $\eta=0$ at $\mathrm{E}=0.0 \mathrm{~V}$ ), the value of $\mathrm{k}_{\mathrm{MPA}}^{0}$ thus represents the slowest rate constant of the kinetic distribution since all other sites experience $\eta>0$ at $\mathrm{E}=0$ and thus have larger rates (see Table II). In this sense it is unsurprising that the $\Delta \mathrm{E}_{\mathrm{PEAK}}$-only evaluation $\left(\mathrm{k}_{\mathrm{AV}}^{0}\right)$ seems to moderately favor the "faster" reacting sites in a distribution modelled as a Gaussian spread of $E^{\circ}$, values.

Although the above difference between $\mathrm{k}_{\mathrm{MPA}}^{0}$ and $\mathrm{k}_{\mathrm{AV}}^{0}$ is not very large, it is important to examine whether it is potential scan rate, temperature or chain length dependent since that would cause the kinetic dispersion to bias the measurement of $\lambda$ (from an 
activation plot) and then $\beta$ (from a plot of $\ln$ (rate constant) vs. chain length).

That is, it is important to know if $\mathrm{k}_{\mathrm{MPA}}^{0}$ and $\mathrm{k}_{\mathrm{AV}}^{0}$ differ by a constant or a changing factor. Voltammograms simulated based on the $\mathrm{k}_{\mathrm{MPA}}^{0}$ value but at much faster scan rates, and then evaluated using only their $\Delta \mathrm{E}_{\mathrm{PEAK}}$ values, yield results for $\mathrm{k}_{\mathrm{AV}}^{0}$ (Table II) that differ from $\mathrm{k}^{0}{ }_{\mathrm{MPA}}$ by the same factor as that obtained at $0.01 \mathrm{~V} / \mathrm{s}$. To address the temperature dependence of $\mathrm{k}_{\mathrm{AV}}^{0}$, comparisons like that made at $135 \mathrm{~K}$ were simulated at 125,150 , and $170 \mathrm{~K}$; the results are shown in Table II (see footnote b). As at $\mathrm{T}=135 \mathrm{~K}$, the $\mathrm{k}_{\mathrm{AV}}^{0}$ method favors the faster reacting (at the average $\mathrm{E}^{\circ}$ ) sites of the distribution at these other temperatures, but by nearly the same factor. The magnitude of the nearly temperature independent bias would cause, in this example, only $-4 \%$ error in $\lambda$ and +3 -fold increase in $\mu \rho$ values derived for the $\mathrm{C} 12$ monolayer from an activation plot. The former difference, and probably the latter, are well within experimental uncertainty. Thus, we conclude that an $\mathrm{E}^{0}$-based kinetic dispersion has little or no consequence on measurement of $\lambda$ from $\Delta \mathrm{E}_{\text {PEAK }}$ values, and perhaps a modest increase in the derived $\mu \rho$. The $c a$. 6-fold difference between $\mathrm{k}_{\mathrm{AV}}^{0}$ and $\mathrm{k}_{\mathrm{MPA}}^{0}$ can be expected to vary with the $\sigma\left(\mathrm{E}^{\circ}\right)$ of the particular monolayer system.

Comparisons of the temperature dependencies of experimental $\mathrm{E}_{\mathrm{FWHM}}$ (Table I) with simulations involving $\mathrm{E}^{\mathrm{o}}$ ' distribution (Table II) show that both $\mathrm{E}_{\mathrm{FWHM}}$ values decrease gradually with increasing temperature. The slight differences between them are well within experiment-to-experiment variability, indicating that $\sigma\left(\mathrm{E}^{0}\right)$ is nearly independent of temperature. The trend in both is opposite to the thermal broadening anticipated from $\mathrm{E}_{\mathrm{FWHM}}, \mathrm{BV}$ and $\mathrm{E}_{\mathrm{FWHM}}, \mathrm{M}-\mathrm{DOS}$ calculations (Table $\mathrm{I}$ ). $\mathrm{E}_{\mathrm{FWHM}}$ changes less with temperature for the Marcus-DOS than the Butler-Volmer predictions (see Table I), owing to increased 
peak overpotential with decreased temperature and subsequent peak broadening that tends to offset slightly the thermal narrowing. Kinetic dispersity apparently magnifies the latter effect in causing the observed peak narrowing with increased temperature.

The Marcus-DOS calculations of $\mathrm{E}_{\mathrm{FWHM}}$ in Table I predict an increase in $\mathrm{E}_{\mathrm{FWHM}}$ with increased chain length; this is caused by the decreasing rate constant $\mathrm{k}^{0}$ with increased chain length and consequent increased $\eta$ relative to reorganization energy. Similarly, a decreased chain length should have the opposite effect.

To investigate the potential effects of chain length on the difference between $\mathrm{k}_{\mathrm{MPA}}^{0}$ and $\mathrm{k}_{\mathrm{AV}}^{0}$ (and the size of a Gaussian distribution of $\mathrm{E}^{0}$, required to fit experimental data), a cyclic voltammogram for a (ferrocenylcarboxy)-octanethiol+octanethiol mixed monolayer at $135 \mathrm{~K}$ (see Table I) was fit in the manner of Figure 2. The best fit voltammogram produced a midpoint average $\mathrm{k}_{\mathrm{MPA}}^{0}=1.10 \times 10^{-2} \mathrm{~s}^{-1}$ and $\sigma\left(\mathrm{E}^{0}\right)=47 \mathrm{mV}$, and the $\Delta \mathrm{E}_{\mathrm{PEAK}}$ of this voltammogram produced an average $\mathrm{k}_{\mathrm{AV}}^{0}=6.0 \times 10^{-2}$. This distribution size is only slightly smaller than that for the $\mathrm{C} 12$ monolayer $(55 \mathrm{mV})$, indicating a minimal chain length dependence of the $\mathrm{E}^{\circ}$ ' distribution. The difference between $\mathrm{k}_{\mathrm{MPA}}^{0}$ and $\mathrm{k}_{\mathrm{AV}}^{0}$ is 5.5 -fold for the C8 monolayer, similar to the 5.8 -fold difference for the $\mathrm{C} 12$ monolayer at the same temperature. The small difference between these factors would translate into a $\beta$ that is smaller by $c a .2 \%$ than that for homogeneous populations for the two chain lengths. The lack of dependence of the $\mathrm{k}_{\mathrm{AV}}^{0}$ analysis on both potential scan rate (Table II) and chain length is internally consistent since both produce changes in $\Delta \mathrm{E}_{\mathrm{PEAK}}$.

Calculations based on fitting Equation 2 with a Gaussian $\mathrm{E}^{\circ}$ ' distribution to experimental voltammograms are quite tedious. Determinations of $\sigma\left(\mathrm{E}^{0}\right)$ with Butler-Volmer 
kinetic Equations 1a, $1 \mathrm{~b}$ give values similar (but somewhat larger, $\sigma\left(\mathrm{E}^{0}\right.$ ) $=71 \mathrm{mV}$ for the best fit to Figure 1) to those determined with the Marcus-DOS Equation 2, and are computationally simpler. (The difference between Butler-Volmer and Marcus-DOS wavebroadening occurs even for homogeneous populations of reacting sites.) Since the ButlerVolmer based calculations of $\sigma\left(\mathrm{E}^{0}\right)$ are simpler, the experimental $\sigma\left(\mathrm{E}^{0}\right)$ results in Table I for different chain lengths and temperatures are derived in this manner, using Equations 1a, $1 \mathrm{~b}$. Other Wave-Broadening Effects. Other possible sources of voltammetric waveshape broadening, include (i) double-layer effects, (ii) uncompensated resistance, and (iii) a real dispersion of rate constants (vide infra). Double-layer effects for redox-active monolayers have been described theoretically by Smith and White ${ }^{41}$ and experimentally observed by Rowe and Creager ${ }^{6 \mathrm{a}}$. In the present experiments the supporting electrolyte concentration is relatively small $(0.075 \mathrm{M})$ and the actual ion population probably even smaller due to ion pairing at low temperatures. Also, $\Gamma_{\mathrm{Fc}}$ is moderately high (1/3 of a full monolayer). Since such factors have in double layer simulations been shown to cause wave broadening, we calculated voltammograms to explore them. ${ }^{42}$ The calculations predict $\mathrm{E}_{\mathrm{FwHM}}$ values (70 $\mathrm{mV}$ at $125 \mathrm{~K}$ and $83 \mathrm{mV}$ at $150 \mathrm{~K}$ ) much smaller than those observed (Table I), and additionally a skewing of the waveshape ${ }^{6 a, 41}$. These observations suggest that double-layer effects are not the dominant waveshape-broadener in our experiments. Additionally, ion-pairing of surfaceconfined ferricenium with $\mathrm{PF}_{6}^{-}$is highly probable at low temperature; double-layer effects would vanish on a thus-neutralized surface. It is known, for example, that $\mathrm{PF}_{6}{ }^{-}$ion-pairs with electrogenerated ferricenium in monolayers containing ferrocenylalkanethiols in aqueous electrolyte at room temperature. ${ }^{6, d}$ Lastly, penetration of ions into the nominally pure 
hydrocarbon region of the monolayer, as suggested by the capacitance data in Table I, may screen the electric charge from the redox centers thus eliminating any double-layer effect.

We next consider uncompensated resistance $\left(R_{U N C}\right)$ as a source of voltammetric broadening. Positive feedback compensation is utilized in these experiments to correct for uncompensated resistance, and it can be expected that the instrumental compensation is always less than $100 \%$ of $R_{U N C}{ }^{43}$ Typical values of $R_{U N C}$ that are corrected for with the positive feedback system are between $1 \times 10^{6}$ to $1 \times 10^{5}$ ohms in the temperature range of $125 \mathrm{~K}$ to $150 \mathrm{~K}$. Direct $\mathrm{AC}$ impedance measurements of $\mathrm{R}_{\mathrm{UNC}}$ generally agree with the instrumental settings. It is important to realize that even at slow potential scan rates, the slow electron transfer rates characteristic of low temperatures (and tunnelling barriers) can give large $\Delta \mathrm{E}_{\mathrm{PEAK}}$ values (Table $\mathrm{I}$ ) and small peak currents in voltammograms (a few nanoamps or less), so that $i R_{U N C}$ is small relative to $\Delta E_{P E A K}$ even though the $R_{U N C}$ remaining after feedback compensation is by usual electrochemical standards rather large. As a result, experimental voltammograms are often quite similar with and without positive feedback. Calculations of cyclic voltammograms with Marcus-DOS kinetics (Equation 2) based on the best fit parameters to the data in Figure 1 and including the effect of an $R_{U N C}=2 M \Omega,{ }^{4 a, 44}$ predict no additional waveshape broadening (beyond that reported in Table I) at a potential scan rate of $5 \mathrm{mV} / \mathrm{s}$, and an increased broadening of $5 \mathrm{mV}$ at a potential scan rate of $10 \mathrm{mV} / \mathrm{s}$. It is therefore unlikely that the $\Delta \mathrm{E}_{\mathrm{PEAK}}$ or $\mathrm{E}_{\mathrm{FWHM}}$ results reported in Table I are caused by uncompensated resistance.

Lastly, waveshape broadening can result from a real distribution of standard rate constants, such as caused by a distribution of tunneling distances or of reorganization barrier 
energies; this is discussed later.

Effects of a Gaussian Distribution of $E^{0}$ on Potential Step Experiments. In potential step experiments, a Gaussian distribution of $\mathrm{E}^{0}$, values provokes an apparent distribution of electron transfer rates because the applied overpotential $\eta$ is reckoned with respect to the average $\mathrm{E}^{0}$, of the redox couple. The effective overpotential experienced by any given redox site will vary with its microscopic formal potential, resulting in a distribution of reaction rates over the ensemble of surface redox sites and a consequent decay of current with time which is not strictly first order. This apparent rate dispersion may of course occur concurrently with a real dispersion of standard rate constants for different reacting sites.

The first order reaction of a surface-confined species is expected ${ }^{2 a}$ to display an exponentially decaying current,

$$
i(t)=k_{A P P, \eta} Q \exp \left[-k_{A P P, \eta} t\right]
$$

where $k_{\mathrm{APP}, \eta}\left(\mathrm{s}^{-1}\right)$ is the sum of the forward and reverse electron transfer rate constants $\left(\mathrm{k}_{\mathrm{ox}, \eta}\right.$ $+\mathrm{k}_{\mathrm{red}, \eta}$ ) at the effective overpotential $\eta$, and $\mathrm{Q}$ is the charge passed in the electron transfer reaction.

Current-time responses to applications of effective overpotential (applied potential relative to the average $\left.\mathrm{E}^{0}\right)$ and for given values of $\sigma\left(\mathrm{E}^{0}\right)$ and $\Gamma_{\mathrm{Fc}}$ were calculated following Equation 5. In these calculations, the rate constant $\mathrm{k}_{\mathrm{APP}, \eta}$ depends on the effective overpotential as in Equation 2, while $\mu \rho$ and $\lambda$ are assumed to be constant. To calculate the current-time curves, the total charge for the reacting monolayer was divided into 21 segments, each with its own $\mathrm{E}^{0}$. The size of each charge segment is determined by 
multiplying the total charge by the normalized intensity of the Gaussian function at each given $\mathrm{E}^{0},{ }^{45}$ The objective was to generate plots of $\log \left[\mathrm{k}_{\mathrm{APP}, \eta}\right]$ vs. effective $\eta$, to be analyzed by best fits to Equation 2 to see whether the determined kinetic parameters $\lambda, \mu \rho$, and $\mathrm{k}^{0}$ differ from the values pertinent to a surface population having a single $\mathrm{E}^{\mathrm{o}}$, value equal to the average $\mathrm{E}^{\mathrm{o}}$.

Figure $3 \mathrm{~A}$ and $3 \mathrm{~B}$ show calculated $125 \mathrm{~K}$ current-time responses, plotted as $\log [\mathrm{i}] v s$. time according to Equation 5, for potential steps to $\eta=0.0 \mathrm{~V}$ and $0.25 \mathrm{~V}$, respectively, with respect to the average $\mathrm{E}^{0}$, each assuming $\Gamma_{\mathrm{Fc}}=1.3 \times 10^{-10} \mathrm{~mol} / \mathrm{cm}^{2}$, and for $\sigma\left(\mathrm{E}^{0}\right)$ values ranging from 0 to $100 \mathrm{mV}$. $\mathrm{k}_{\mathrm{APP}, \eta}$ for each $\eta$ was calculated from Equation 2 using $\lambda=$ $0.80 \mathrm{eV}$ and $\mu \rho=1 \times 10^{6} \mathrm{~s}^{-1} \mathrm{eV}^{-1}$. Figure $3 \mathrm{~A}$ (curve E) and $3 \mathrm{~B}$ (curve D) correspond to no dispersion in $\mathrm{E}^{\mathrm{o}}$, and yield linear $\log [\mathrm{i}]$ vs. time plots. All others are curved. The extent of curvature increases with increasing formal potential dispersion $\sigma\left(\mathrm{E}^{0}\right)$, i.e., an increasing dispersion in the apparent reaction rate. The difference in rate (slope) for $\sigma\left(\mathrm{E}^{0}\right)=60 \mathrm{mV}$ between the shortest and longest times is about 10 -fold. Clearly the sites that experience a greater effective overpotential generate more current at shorter times and dominate the response there, whereas sites experiencing a smaller effective overpotential dominate at longer times. The faster sites dominate over the time range shown for $\eta=0$ and $\sigma\left(\mathrm{E}^{0}\right)>$ 0 , and the slope lies above the actual rate except at the largest times, whereas for $\eta=0.25$ $\mathrm{V}$, the average slope $\left(\mathrm{k}_{\mathrm{ave}}\right)$ passes from higher to lower than the actual rate near the middle of the plot.

Figure 4 shows, for comparison, a $\log [i] v s$. time plot of typical experimental data at $125 \mathrm{~K}$ and $\eta=0.2 \mathrm{~V}$ for a monolayer of (ferrocenylcarboxy)-dodecanethiol coadsorbed with 
dodecanethiol. The plot in Figure 4 is curved with a 4-fold difference in rate from longest to shortest times. Other potential step experiments in $\mathrm{EtCl} / \mathrm{PrCN}$ at low temperature have given similarly curved $\log [\mathrm{i}] v s$. time responses ${ }^{31}$ regardless of chain length, temperature, or applied overpotential. Others have seen such curvature. ${ }^{2 c}$ The calculations shown in Figure 3 demonstrate that a distribution of formal potentials $\sigma\left(\mathrm{E}^{0}\right)$ selected to fit a broadened cyclic voltammogram (i.e., Figure 2), produces $\log [\mathrm{i}] v$ s. time plots that are curved in a manner similar to that observed experimentally (Figure 4).

The more significant issue is whether the curved $\log [\mathrm{i}] v s$. time plots described above translate into any substantial bias when they are analyzed according to Equation 2 for apparent values of $\mathrm{k}^{0}, \lambda$, and $\mu \rho$. Figure 5 shows three $\log \left[\mathrm{k}_{\mathrm{APP} . \eta}\right] v s . \eta$ plots generated from calculated $125 \mathrm{~K}$ current-time plots with $\sigma\left(\mathrm{E}^{0,}\right)=45 \mathrm{mV} . \mathrm{k}_{\mathrm{APP}, \eta}$ for each $\eta$ was calculated from Equation 2 using values of $\lambda$ and $\mu \rho$ of $0.80 \mathrm{eV}$ and $1 \times 10^{6}$ respectively. The overpotential range shown in Figure 5 is typical of that currently accessible in our experiments $^{31}$. Due to the curvature of the $\log [\mathrm{i}] v s$. time plots, the total faradaic reaction charge was divided into ten equal segments and the rate constant evaluated for each segment from the average slope during the time interval over which that charge segment is passed. This procedure allows the determination of rates for the same population of ferrocene sites as a function of applied overpotential. Figure $5(\square, \nabla, \diamond)$ correspond to the indicated ferrocene charge segments, i.e., the first $0-10 \%$ of reacting sites, the $30-40 \%$ of reacting sites, etc.

Figure 5 also shows a plot $(\mathrm{O})$ for an ideal homogeneous population $\left(\sigma\left(\mathrm{E}^{0}\right)=0 \mathrm{mV}\right)$ of redox sites. This ideal curve $(O)$ lies below the calculated ones and exhibits less curvature 
at higher applied $\eta$ values. The calculated $\log \left[\mathrm{k}_{\mathrm{APP}, \eta}\right] v s . \eta$ plot for each charge segment in Figure 5 was compared to Equation 2 to extract a best fit for $\mathrm{k}^{\circ}, \lambda$, and $\mu \rho$. The results at $125 \mathrm{~K}$ are summarized in Table III. The best fit to the first $(0-10 \%$ reacting) charge segment produces $\lambda=0.55 \mathrm{eV}, \mu \rho=5.4 \times 10^{4} \mathrm{~s}^{-1} \mathrm{eV}^{-1}$, and $\mathrm{k}^{0}=5.0 \times 10^{-3} \mathrm{~s}^{-1}$. The apparent values of $\lambda$ and $\mu \rho$ are smaller and that for $\mathrm{k}^{0}$ larger than values for a kinetically homogeneous population $\left(\sigma\left(\mathrm{E}^{0}\right)=0 \mathrm{mV}\right)$. The later charge segments give values of $\lambda, \mu \rho$, and $\mathrm{k}^{0}$ that are more similar to but still considerably different from the ideal values, especially $\mu \rho$. Similar calculations (Table III) show that the distortion in the derived kinetic parameters is less at higher temperature and substantially greater for larger $\sigma\left(\mathrm{E}^{0}\right)$. It is significant, however, that the average rate constants for later charge segments, i.e., in the second one-half of the reacting population, differ from the ideal standard rate constant $k^{\circ}$ by less than two-fold. For this reason we regard $\mathbf{k}^{\mathbf{o}}$ data derived from experimental potential step results that exhibit kinetic dispersity (i.e., Figure 4) in the manner of Figure 5 as reliable to a ca. a factor of two, as long as the analysis is confined to the later-reacting surface population. Similarlyderived values of $\lambda$ and $\mu \rho$ are more suspect.

A comparison of the homogeneous rate and that derived at each charge segment for simulated potential step experiments is analogous to comparing $\mathrm{k}_{\mathrm{MPA}}^{0}$ and $\mathrm{k}_{\mathrm{AV}}^{0}$ derived from simulated cyclic voltammograms. Recall that best fit voltammograms are such that the difference between $\mathbf{k}_{\mathrm{MPA}}^{0}$ and $\mathrm{k}_{\mathrm{AV}}^{0}$ is approximately 6-fold; a similar difference in rates for potential step simulations is found between the rate determined from the third to fourth segment and the average rate (i.e. the rate determined with no distribution). The significance of this observation is tenuous, however, because the rates determined for charge segments 
are complicated by the unusually low value of $\lambda$ necessary to fit the Tafel plot.

Finally, another possible reason for curved $\log [\mathrm{i}] v s$ time plots is charge effects within the electrical double layer as described by Weber and Creager ${ }^{46}$. As previously stated, we consider that double-layer effects are probably minimal in our experiments due to ionpairing. Also, $\log [i] v s$. time plots exhibit the same magnitude of curvature for oxidative and reductive overpotential steps (data not shown), which is not predicted by the double-layer model.

Kinetic Dispersion Modelled as a Gaussian Distribution of Reorganizational Energy Barriers or Tunneling Distances. Kinetic dispersion can of course be real and not apparent as in the $\mathrm{E}^{\mathrm{o}}$ distribution discussed above. Of the several forms of kinetic heterogeneity in electroactive SAM's, we consider (i) a distribution of reorganizational barrier energies $\lambda$ (such as might result from variable ferrocene/monolayer/solution interactions), and (ii) a distribution of tunnelling distances or electronic coupling factors (such as might arise from monolayer disorder).

Consider a distribution in $\lambda$. A monolayer with ferrocene sites that exhibit a distribution of $\lambda$ values (but a uniform $\mathrm{E}^{0}$ ) will generate a kinetic dispersion that is real but which in appearance is very similar to the apparent dispersion caused by a distribution in $\mathrm{E}^{0}$, at constant $\lambda$. The similarity occurs because $\mathrm{E}^{0}$ (as $\eta$ ) and $\lambda$ both appear in the exponential of Equation 2. $\mathrm{E}^{\mathrm{o}}$ and $\lambda$ dispersions under conditions approaching reversibility (i.e., very slow potential scan rates, higher temperatures, shorter alkyl chains) would however produce differing voltammetry; for the former dispersion, broadened waveshapes would persist, whereas for the latter the waveshape would become ideal. It seems likely that in reality $\lambda$ or 
$\mathrm{E}^{0}$, dispersity will occur together, both contributing to the kinetic behavior, and making their deconvolution difficult.

Kinetic dispersion can also appear as a distribution in the electronic coupling parameter $\mu$, which depends ${ }^{28}$ exponentially on distance, $\mathrm{d}$,

$$
\mu=\mu_{0} \exp \left(-\beta\left(d-d_{0}\right)\right)
$$

where $\mu_{0}$ represents the coupling ${ }^{38 b}$ at the smallest electrode-redox molecule separation distance $\mathrm{d}_{0}$ and $\beta$ is the electronic coupling parameter or distance decay constant. Thus a distribution of either the distance over which electron transfer occurs or the coupling term $\beta$ (by chain conformational changes ${ }^{47}$ ) would result in a distribution of $\mu$ and thus a dispersion in the reaction rate. This dispersion was modelled by assuming that at the moment of electron transfer a Gaussian distribution of distances exists over which electron transfer can occur. (The spread in this distribution is implied to depend on the degree of monolayer disorder.)

Figure 6 shows a $\log [\mathrm{i}]$ vs. time plot for a Gaussian distribution of distances, leading to a distribution of $\mu$ as described by Equation 6, for a monolayer with other parameters as in Figure 1, an average ferrocene distance of $14 \AA$ from the electrode surface, and an overpotential of $0.25 \mathrm{~V}$ at $125 \mathrm{~K}$. The standard deviation of the distance, $\sigma(\mathrm{d})=1.54 \AA$ is taken as the length of a carbon-carbon spacing in an n-alkane and a constant value of $\beta=$ $1.08 \AA^{-1}$. The simulated transient (Figure 6) was determined with Equation $4, \Gamma_{\mathrm{Fc}}=1.3 \mathrm{x}$ $10^{-10} \mathrm{~mol} / \mathrm{cm}^{2}$, and a rate constant that in Equation 2 corresponds to $\lambda=0.80 \mathrm{eV}$, and $\mu \rho_{\text {ave }}$ $=6 \times 10^{6} \mathrm{~s}^{-1} \mathrm{eV}^{-1}$ at an average distance of $14 \AA$. The value of $\mu$ varies from $\pm 3^{*} \sigma(\mathrm{d})$, 
according to Equation 6 . Figure 6 shows a pronounced curvature, indicative of kinetic dispersion as anticipated. The rate determined from the slope of Figure 5 is greatest at shorter times and varies by over an order of magnitude.

Tafel plots derived from a charge segment analysis of Figure 6 (similar to that of Figure 5) are shown as Figure 7, with best fit parameters for charge segments 1, 4, and 7 listed in Table IV. As expected, the results vary with the charge segment. Segment 4 yields values of $\lambda, \mu \rho$, and $\mathrm{k}^{0}$ close to the original (no dispersion) values. Interestingly, $\lambda$ varies only mildly with charge segment, which is a significant difference between this type of kinetic dispersion and that due to a Gaussian distribution of $\mathrm{E}^{0}$. The minor variation in $\lambda$ seems reasonable since the dispersion is in the pre-exponential term, which contains only a weak dependence ${ }^{38 b}$ on $\lambda$. The other variables, $\mu \rho$ and $\mathrm{k}^{0}$, do however change considerably from one charge segment to the next.

It is instructive to examine the physical aspects of a self-assembled monolayer that could lead to a kinetic dispersion through Equation 6. Several studies have deduced similar $\beta$ values, 1.0 to $1.1 / \mathrm{CH}_{2}$ for electron transfers through $\mathrm{n}$-alkanethiol monolayers on gold. ${ }^{1 \mathrm{a}, 1 \mathrm{c}, 2 \mathrm{a}, 48-50} \beta$ was also determined to be independent of the electrode potential, consistent with a through-bond tunneling mechanism. ${ }^{1 c, 47,51}$ Similar $\beta$ values result from kinetic studies with immobilized ${ }^{1 \mathrm{a}, 1 \mathrm{c}, 2}$ and with soluble redox probes $^{48,49}$ at SAM's, suggesting that the mechanism for electron transfer across the monolayer is similar for these different physical situations, i.e., the tunnelling barriers are similar for electron transfers through coadsorbed $n$-alkanethiols and through the chain of the redox probe. In fact, recent results by Finklea ${ }^{52 a}$ support the notion of electron transfer through the diluent alkanethiol in mixed 
alkanethiol/redox-active alkanethiol monolayers.

Since the termini of (ideally, all trans) SAM alkane chains are known to have gauche defects $^{1 c}$, and defects there and in the chain interior may be more pronounced in organic solvents, it is reasonable to suppose that variances can occur in distance $d$ or in the orientation of the chains $(i . e ., \beta)$. Super-exchange calculations ${ }^{47}$ for the electron transfer of donor-acceptor molecules predict substantial changes in coupling with alkyl orientation. For example, a single gauche bond in the middle of an all-trans $n$-alkane chain is calculated ${ }^{47 h}$ to decrease the coupling matrix $\left(\mathrm{H}_{\mathrm{AB}}\right)$ by a factor of twenty (from $\left.76-1591 \mathrm{~cm}^{-1}\right)$, which translates into a factor of two-fold change in $\beta$. Gauche defects concurrently ${ }^{47 j}$ produce a change in d (measured normal to the surface), so dispersion through Equation 6 requires inter-related $\sigma(\mathrm{d})$ and $\sigma(\beta)$ dispersions. Experimentally, an alkylsiloxide SAM has been observed ${ }^{47 \mathrm{~h}}$ to exhibit a larger tunneling barrier upon annealing to introduce gauche defects. Correlating monolayer structure (disorder) and coupling and thus electron transfer rate dispersion in SAM's is an interesting experimental prospect which will require application of other structure-sensitive techniques.

A more detailed examination of the consequences of a distribution of tunneling distances is possible, particularly in regards to fitting experimental cyclic voltammograms, but since we have little structural information regarding our system, and since simulated Tafel plots with such distributions did not agree well with our experimental results, we did not pursue this notion. It is clear from the above discussion how one would go about doing so, and may be more appropriate for other systems.

Summary A Gaussian distribution of $\mathrm{E}^{0}$, with $\sigma\left(\mathrm{E}^{0}\right)$ of approximately $55 \mathrm{mV}$ is consistent 
with the experimentally observed waveshape broadening in cyclic voltammetric experiments and the curvature in $\log (i)$ vs. time plots derived from potential step experiments. Interestingly, fitting kinetic parameters to Tafel plots derived from calculated potential step experiments that account for a Gaussian distribution of $\mathrm{E}^{0}$, gives low values of $\lambda$ and $\mu \rho$ and high values of $\mathrm{k}^{0}$ as compared to the true values (i.e. those expected with a homogeneous population of kinetic sites) at the earliest charge segments, and approach but do not equal the true values at later ones. Thus, analyzing Tafel data derived from potential step experiments with monolayers having kinetic dispersion caused by a Gaussian distribution of $\mathrm{E}^{0}$, can yield erroneously low values of $\lambda$ and $\mu \rho$ and high values of $\mathrm{k}^{0}$. Error in $\mathrm{k}^{\circ}$ can be reduced to $\underline{c a}$. two-fold by reliance on later charge segments. Results from cyclic voltammetric simulations give an average rate constant roughly 6-fold larger than the mid-point average rate constant incorporating a Gaussian $\mathrm{E}^{\mathrm{o}}$ distribution. This bias is nearly temperature and chain length tindependent and does not significantly effect values of $\lambda$ and $\mu \rho$ determined from activation plots or determination of $\beta$. Finally, a Gaussian distribution of reorganizaiton energies, which is real Kinetic dispersion, has consequences on the appearance and the analysis of data qualitatively equivalent to those of a distribution of formed potentials.

Kinetic heterogeneity caused by a Gaussian distribution of tunneling distances has also been considered. Tafel plots derived from these simulations result in best fit values of $\mu \rho$ and $\mathrm{k}^{0}$ that are higher than the true values at early charge segments, nearly the same at intermediate segments, and lower at later ones. The value of $\lambda$ is nearly the same as the true value at all charge segments, which is a significant difference between this type of kinetic heterogeneity and that of a Gaussian distribution of $\mathrm{E}^{0}$. Therefore this type of kinetic 
heterogeneity can, in principle, be distinguished from a Gaussian distribution of $\mathrm{E}^{0}$, based on its ability to render values of $\lambda$ that are in accord with less dispersion-sensitive approaches $^{3,4,31}$ like cyclic voltammetric $\Delta \mathrm{E}_{\mathrm{PEAK}}$ analysis or activation plots.

Predictions made with a Gaussian $\mathrm{E}^{0}$, distribution appear to give the most consistent agreement with experimental cyclic voltammetric and potential step results and is therefore favored as the likely cause of apparent kinetic heterogeneity.

ACKNOWLEDGEMENT. This research was supported by grants from the Office of Naval Research and the National Science Foundation. 


\section{REFERENCES}

1. (a) Chidsey, C. E. D. Science 1991, 251, 919. (b) Chidsey, C. E. D.; Bertozzi, C. R.;

Putvinski, T. M.; Mujsce, A. M. J. Am. Chem. Soc. 1990, 112, 4301. (c) Dubois, L. H.; Nuzzo, R. G. Annu. Rev. Phys. Chem. 1992, 43, 437.

2. (a) Finklea, H. O.; Hanshew, D. D. J. Am. Chem. Soc. 1992, 114, 3173. (b) Finklea,

H. O.; Ravenscroft, M. S.; Snider, D. A. Langmuir 1993, 9, 223.

(c) Finklea, H. O.; Ravenscroft, M. S. J. Phys. Chem. 1994, 98, 3843.

3. Curtin, L. S.; Peck, S. R.; Tender, L. M.; Murray, R. W.; Rowe, G. K.; Creager, S.

E. Anal. Chem. 1993, 65, 386 .

4. (a) Tender, L. M.; Carter, M. T.; Murray, R. W. Anal. Chem. 1994, 66, 3173. (b)

Creager, S. E.; Weber, K. Anal. Chem. 1994, 66, 3164.

5. Nahir, T. M.; Clark, R. A.; Bowden, E. F. Anal. Chem. 1994, 66, 2595.

6. (a) Rowe, G. K.; Creager, S. E. J. Phys. Chem. 1994, 98, 5500. (b) Creager, S. E.;

Rowe, G. K. Langmuir 1993, 9, 2330. (c) Creager, S. E.; Rowe, G. K. Anal. Chim. Acta 1991, 246, 233. (d) Rowe, G. K.; Creager, S. E. Langmuir 1991, 7, 2307. (e) Creager, S. E.; Hockett, L. A.; Rowe, G. K. Langmuir 1992, 8, 854.

7. Katz, E.; Itzhak, N.; Willner, I. Langmuir 1993, 9, 1392.

8. Song, S.; Clark, R. A.; Bowden, E. F.; Tarlov, M. J. J. Phys. Chem. 1993, 97, 6564.

9. Shimazu, K.; Yagi, I.; Sato, Y.; Uosaki, K. Langmuir 1992, 8, 1385.

10. Collard, D. M.; Fox, M. A. Langmuir 1991, 7, 1192.

11. Hong, H.; Mallouk, T. E. Langmuir 1991, 7, 2362.

12. Hickman, J. J.; Ofer, D.; Zou, C.; Wrighton, M. S.; Laibinis, P. E.; Whitesides, G. 
M. J. Am. Chem. Soc. 1991, 113, 1128.

13. Tsutsumi, H.; Furumoto, S.; Morita, M.; Matsuda, Y. J. Electrochem. Soc. 1992, 139, 1522.

14. Creager, S. E.; Rowe, G. K. J. Electroanal. Chem. 1994, 370, 203.

15. De Long, H. C.; Donohue, J. J.; Buttry, D. A. Langmuir 1991, 7,2196.

16. Duevel, R. V.; Corn, R. M. Anal. Chem. 1992, 64, 337.

17. Hickman, J. J.; Ofer, D.; Laibinis, P. E.; Whitesides, G. M.; Wrighton, M. S. Science 1991, 252, 688 .

18. Popenoe, D. D.; Deinhammer, R. S.; Porter, M. D. Langmuir 1992, 8, 2521.

19. (a) Uosaki, K.; Sato, Y.; Kita, H. Electrochim. Acta 1991, 36, 1799. (b) Uosaki, K.;

Sato, Y.; Kita, H. Langmuir 1991, 7, 1510.

20. Clark, B. J.; Cleland, W. E.; Hussey, C. L. J. Electrochem. Soc. 1992, 139, L107.

21. De Long, H. C.; Buttry, D. A. Langmuir 1992, 8, 2491.

22. Bunding-Lee, K. A. Langmuir 1990, 6, 709.

23. Katz, E.; Borovkov, V. V.; Evstigneeva, R. P. J. Electroanal. Chem. 1992, 326, 197.

24. Zhang, L.; Lu, T.; Gokel, G. W.; Kaifer, A. E. Langmuir 1993, 9, 786.

25. Redepenning, J.; Tunison, H. M.; Finklea, H. O. Langmuir 1993, 9, 1404.

26. Obeng, Y. S.; Bard, A. J. Langmuir 1991, 7, 195.

27. (a) Caldwell, W. B.; Chen, K.; Mirkin, C. A.; Babinec, S. J. Langmuir 1993, 9, 1945.

(b) Kwan, W. S. V.; Atanasosoka, L.; Miller, L. L. Langmuir 1991, 7, 1419. (c) Kwan, W. S. V.; Penneau, J. F.; Miller, L. L. J. Electroanal. Chem. 1990, 291, 295.

28. (a) Marcus, R. A. J. Phys. Chem. 1963, 67,853. (b) Marcus, R. A. J. Phys. Chem. 
1965, 43,679. (c) Sutin, N. Annu. Rev. Phys. Chem. 1984, 35, 437.

29. Groat, K. A.; Creager, S. E. Langmuir 1993, 9, 3668.

30. (a) Peck, S. R.; Curtin, L.S.; McDevitt, J. T.; Murray, R. W.; Collman, J. P. ; Little, W. A.; Zetterer, T.; Duan, H. M.; Dong, D.: Hermann, A. M. J. Am. Chem Soc. 1992, 114, 6771. (b) Peck, S. R.; Curtin, L.S.; Tender, L.M.; Carter, M.; Terrill, R.H.; Murray, R. W.; Collman, J. P. ; Little, W. A.; Duan, H. M.; Dong, D.; Hermann, A. M. $J$. Am. Chem. Soc., in press

31. (a) Richardson, J. N.; Rowe, G. K.; Carter, M. T.; Murray, R. W. J. Phys. Chem., 1995, 99, 766. (b) Richardson, J. N.; Peck, S. R.; Curtin, L. S.; Tender, L. M.; Terrill, R. H.; Carter, M. T.; Murray, R. W.; Rowe, G. K.; Creager, S. E. Electrochim. Acta, in press.

32. The potentiostat and feedback circuits were designed by S. Woodward, UNC electronics shop.

33. Assuming spherical ferrocene with diameter $6.6 \AA$, hexagonally close-packed gives a $\operatorname{maximum} \Gamma_{\mathrm{Fc}}$ of $4.5 \times 10^{-10} \mathrm{~mol} / \mathrm{cm}^{2}$.

34. Porter, M. D.; Bright, T. B.; Allara, D. L.; Chidsey, C. E. D. J. Am. Chem. Soc. 1987, 109, 3559.

35. Finklea, H. O.; Hanshew, D. D. J. Electroanal. Chem. 1993, 347, 327.

36. $\mathrm{C}_{\mathrm{dl}}$ at naked gold increases by $\underline{c a}$. 3-fold over the temperature range 120 to $180 \mathrm{~K}$. The values of $\mathrm{C}_{\mathrm{dl}}$ at $120,130,140,150,160,170$ and $180 \mathrm{~K}$ are $9.8,12.5,14.6,15.5,16.5,17$, and $29 \mu \mathrm{F} / \mathrm{cm}^{2}$ respectively.

37. (a) Laviron, E. J. Electroanal. Chem. 1974, 52, 355, 395. (b) Bard, A. J.; Faulkner, 
L. F. Electrochemical Methods. (c) Albery, W. J.; Boutelle, M. G.; Colby, P. J.; Hillman, A. R. J. Electroanal. Chem. 1982, 133, 135. (d) The variables in Equations $1 \mathrm{a}, \mathrm{b}$ are $\mathrm{k}_{\mathrm{b}}$ the reverse electron-transfer rate, $\Gamma_{\mathrm{R}}^{*}$ the total electroactive probe coverage, $v$ the scan rate, $\eta$ the applied overpotential $\left(\mathrm{E}-\mathrm{E}^{0}=\Delta \mathrm{E}_{\mathrm{PEAK}} / 2\right), \mathrm{k}_{\mathrm{b}}^{0}$ the standard reverse rate constant, and $\alpha$ the transfer coefficient.

38. (a) In Equation 2, $\mathrm{x}$ denotes a energy state of the metallic electrode, $\mu$ the electronic coupling between the electrode and the redox sites across the n-alkane chain, and $\rho$ the density of states of the metal electrode. (b) The coupling term $\mu$ has a weak $\lambda$ dependence; $\mu=\left(\left|\mathrm{H}_{\mathrm{AB}}\right|^{2} / \hbar\right)(\pi / \lambda \mathrm{kbT})^{1 / 2}$ where $\left|\mathrm{H}_{\mathrm{AB}}\right|$ is the coupling matrix. $\left|\mathrm{H}_{\mathrm{AB}}\right|^{2} \propto \exp (-\beta \mathrm{d})$ so changes in the coupling can directly effect $\beta$.

39. (a) Equation 3 contains a the radius of the electroactive species $(a=3.8 \AA), d$ its (normal) distance from the electrode surface $\left(\mathrm{d}=18.7 \AA, 1.33 \AA / \mathrm{CH}_{2}\right.$ (taken from reference $34)), \epsilon_{\mathrm{op}}, \epsilon_{\mathrm{s}}$, the optical and static dielectric constants of the solvent respectively, $\epsilon_{0}$ the permittivity of vacuum, e the charge of an electron. The inner sphere reorganization, $\lambda_{\mathrm{IS}}$, for ferrocene has been calculated ${ }^{39 b}(0.01 \mathrm{eV})$ and is small compared to $\lambda_{o s}$ in most solvents. The distance per methylene unit was determined by multiplying the number of carbons in the ferrocenealkane chain (plus two to account for the ester group) by the bond length of $1.54 \AA$ for a carbon-carbon bond in a saturated alkane. This value is then multiplied by $\sin \left(60^{\circ}\right)$ to account for the $30^{\circ}$ tilt angle of the monolayer with respect to the surface normal. (b) Gennett, T.; Milner, D. F.; Weaver, M. J. J. Phys. Chem. 1985, 89, 2787. 40. Gudowska-Nowak, E. J. Phys. Chem. 1994, 98, 5257.

41. Smith, C. P.; White, H. S. Anal. Chem. 1992, 64, 2398. 
42. The double layer calculations are for a reversible electron transfer; we assume that the results are similar for irreversible systems. Parameters used are electrolyte concentration $\mathrm{C}_{\mathrm{elec}}=0.075 \mathrm{M}, \Gamma_{\mathrm{Fc}}=1.3 \times 10^{-10} \mathrm{~mol} / \mathrm{cm}^{2}, \mathrm{~T}=125 \mathrm{~K}$ or $150 \mathrm{~K}$, monolayer thickness $\mathrm{d}=$ 15.24 $\AA$, dielectric constant for monolayer and solvent $\epsilon_{\mathrm{ML}}=2.6$ and $\epsilon_{\mathrm{Solv}}=22$, respectively, the charge on the oxidized and reduced redox probe are +1 and 0 respectively, $\mathrm{E}^{0}=0.0 \mathrm{~V}$ (arbitrary), and $\mathrm{E}_{\mathrm{PZC}}=-0.2 \mathrm{~V}$.

43. Milner, D.; Weaver, M. J. J. Electroanal. Chem. 1985, 191, 411.

44. Typically compensation at $\mathrm{T}=135 \mathrm{~K}$ is $3 \times 10^{5} \Omega$. Cyclic voltammograms were generated via digital simulation following Equation 2 such that the potential is corrected at each point by adding $I * R_{u n c}$.

45. Each Gaussian function has been normalized so that the sum of all the Gaussian functions equals one.

46. Creager, S. E.; Weber, K. Langmuir 1993, 9, 844.

47. See for example (a) Closs, G. L.; Calcaterra, L. T.; Green, N. J.; Penfield, K. w.; Miller, J. R. J. Phys. Chem. 1986, 90,3673. (b) Beratan, D. N.; Hopfield, J. J. J. Am. Chem. Soc. 1984, 106, 1584. (c) Hoffman, R. Acc. Chem. Res. 1971, 4, 1. (d) Newton, M. D. Chem. Rev. 1991, 91, 767. (e) Jordan, K. D.; Paddon-Row, M. N. Chem. Rev. 1992, 92, 395. (f) Hoffman, R.; Imamura, A.; Hehre, W. J. J. Am. Chem. Soc. 1968, 90, 1499. (g) Ratner, M. A. J. Phys. Chem. 1990, 94, 4877. (h) Koga, N.; Sameshima, K.; Morokuma, K. J. Phys. Chem. 1993, 97, 13117. (i) Haran, A.; Waldeck, D. H.; Naaman, R.; Moons, E.; Cahen, D. Science 1994, 263, 948. (j) Broo, A.; Laisson, S. Chem. Phys. 1990, 148, 103. 
48. Becka, A. M.; Miller, C. J. Phys. Chem. 1993, 97, 6233.

49. Xu, J.; Li, H-L; Zhang, Y. J. Phys. Chem. 1993, 97, 11497.

50. Carter, M. T.; Rowe, G. K.; Richardson, J. N.; Murray, R. W. J. Am. Chem. Soc.. in press.

51. Simmons, J. G. J. Appl. Phys. 1963, 34, 1793.

52. (a) Finklea, H. O. 208th meeting of the American Chemical Society, Washington, DC, COLL \#0233, August 1994. (b) Gary K. Rowe, UNC 1994 unpublished results. 


\begin{tabular}{|c|c|c|c|c|c|c|c|c|c|c|c|c|c|}
\hline ن & $\begin{array}{l}\widehat{\widetilde{n}} \\
\stackrel{d}{=}\end{array}$ & \pm & $=$ & $=$ & $\vec{\sim}$ & లి & $\stackrel{\sqrt[n]{n}}{=}$ & $\stackrel{\infty}{\sim}$ & $\vec{\lambda}$ & 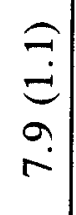 & $=$ & 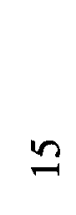 & 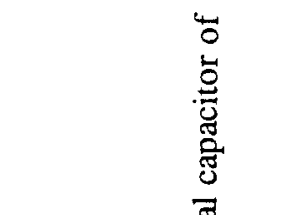 \\
\hline 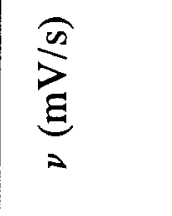 & 으 & त) & శి & ¿ి & तి & 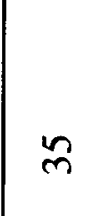 & ㅇ & 의 & 의 & $n$ & $n$ & $n$ & 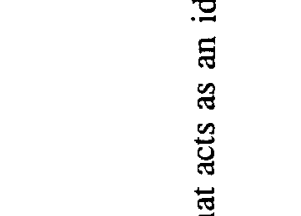 \\
\hline 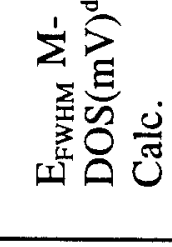 & 8 & 8 & $\widetilde{\sigma}$ & $\widetilde{\sigma}$ & nे & t & $\stackrel{\infty}{\infty}$ & $R$ & 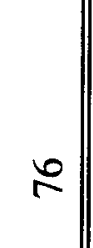 & $\tilde{\infty}$ & $\infty$ & $\infty$ & 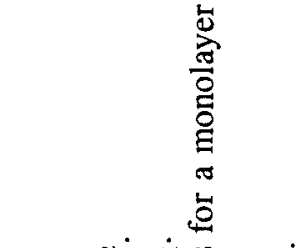 \\
\hline 窟总品 & $i$ & $n$ & $n$ & $\tilde{n}$ & in & $\overline{6}$ & $i$ & in & 8 & $\approx$ & $\hat{n}$ & 8 & 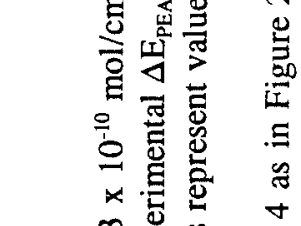 \\
\hline 舒勇总总 & $\vec{\infty}$ & 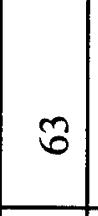 & in & $\begin{array}{l}\widetilde{T} \\
\text { 吾 } \\
\text { n }\end{array}$ & $\mathcal{F}$ & P & $F$ & 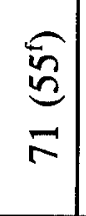 & 8 & $\vec{a}$ & $\vec{\infty}$ & $F$ & 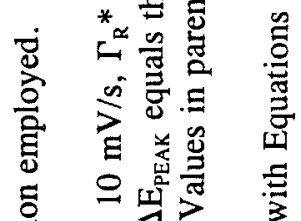 \\
\hline 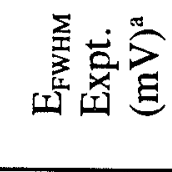 & $\tilde{\Xi}$ & 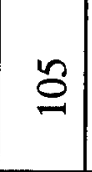 & $\widetilde{\sigma}$ & d & 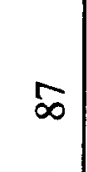 & 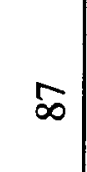 & Iิ & $\exists$ & $\Xi$ & $\hat{m}$ & సి & $\vec{\Xi}$ & 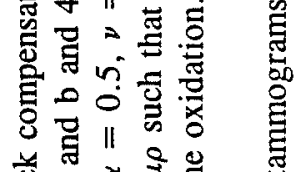 \\
\hline 鸹 & $\underset{\sim}{ \pm}$ & $\stackrel{\infty}{\beth}$ & $\underset{\sim}{\mathbb{\sigma}}$ & సి & $\infty$ & $\approx$ & 志 & 잉 & $\underset{\sim}{ \pm}$ & 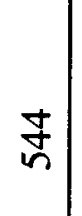 & $\underset{+}{\&}$ & $\tilde{y}$ & 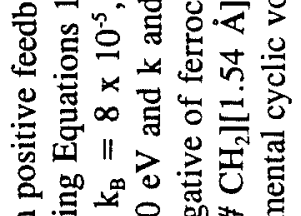 \\
\hline$\widehat{\varepsilon}$ & $\stackrel{త ్}{ }$ & $\cong$ & 吕 & $\stackrel{m}{m}$ & 昌 & 等 & $\approx$ & $\cong$ & $\stackrel{0}{\circ}$ & 尺े & 昌 & ถุ & 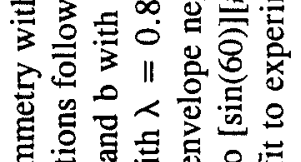 \\
\hline $\begin{array}{l}\overrightarrow{0} \\
\frac{\vec{d}}{0} \\
\stackrel{0}{\Sigma}\end{array}$ & $\begin{array}{l}\overrightarrow{7} \\
0 \\
0 \\
0 \\
0 \\
0 \\
0 \\
0 \\
0 \\
0 \\
0 \\
0\end{array}$ & $=$ & $=$ & $=$ & $=$ & $=$ & 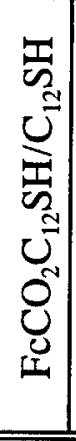 & 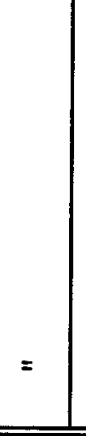 & $=$ & 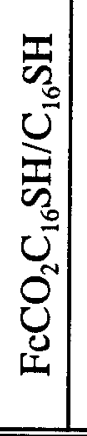 & $=$ & $=$ & 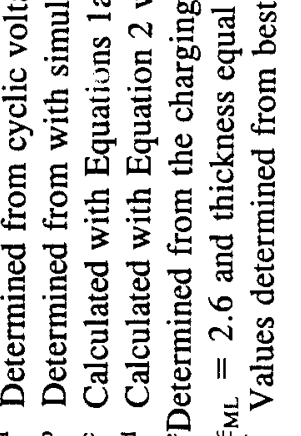 \\
\hline
\end{tabular}


TABLE II. Best Fit Kinetic Results for Simulated Cyclic Voltammetric Waves Exhibiting a Gaussian Distribution of $\mathrm{E}^{0}$, as a Function of Temperature. ${ }^{\mathrm{a}}$

\begin{tabular}{|l|l|l|l|}
\hline $\mathrm{T}(\mathrm{K})$ & $\nu(\mathrm{V} / \mathrm{s})$ & $\mathrm{k}_{A \mathrm{~V}}^{0}\left(\mathrm{~s}^{-1}\right)^{\mathrm{a}}$ & $\mathrm{E}_{\mathrm{FWHM}}(\mathrm{mV})^{\mathrm{c}}$ \\
\hline $125^{\mathrm{b}}$ & & & \\
\hline & 0.01 & $2.80 \times 10^{-4}$ & 118 \\
\hline $135^{\mathrm{b}}$ & 100 & $3.20 \times 10^{-4}$ & 202 \\
\hline & & & \\
\hline & 0.01 & $1.03 \times 10^{-3}$ & 117 \\
\hline & 0.1 & $1.08 \times 10^{-3}$ & 128 \\
\hline & 10 & $1.13 \times 10^{-3}$ & 166 \\
\hline $150^{\mathrm{b}}$ & 100 & $1.24 \times 10^{-3}$ & 202 \\
\hline & & & 115 \\
\hline & 0.01 & $6.0 \times 10^{-3}$ & 198 \\
\hline $170^{\mathrm{b}}$ & 100 & $6.6 \times 10^{-3}$ & \\
\hline & & & 109 \\
\hline & 0.01 & $4.15 \times 10^{-2}$ & 194 \\
\hline
\end{tabular}

${ }^{a}$ Average rates constants determined from the best fit to the $\Delta \mathrm{E}_{\mathrm{PEAK}}$ with Equation 2 and $\lambda=0.80 \mathrm{eV}$ for $a$ simulated voltammogram with a Gaussian distribution of $\mathrm{E}^{0}\left(\sigma\left(\mathrm{E}^{0,}\right)=55 \mathrm{mV}, \mu \rho_{\mathrm{MPA}}=1.48 \times 10^{5} \mathrm{eV}^{-1} \mathrm{~s}^{-1}, \lambda=0.80 \mathrm{eV}\right) . \quad b$ Mid-point average rate of the distribution, $\mathrm{k}_{\mathrm{MPA}}^{0}=1.78 \times 10^{-4} \mathrm{~s}^{-1}$ determined at $135 \mathrm{~K}$ by comparison to experiment as in Figure 2 . Midpoint average rate constants at other temperatures, using $\mu \rho_{\mathrm{MPA}}=1.48 \times 10^{5} \mathrm{eV}^{-1} \mathrm{~s}^{-1}$ and $\lambda=0.80 \mathrm{eV}$, are $4.18 \times 10^{-5} \mathrm{~s}^{-1}(125 \mathrm{~K})$, $1.10 \times 10^{-3} \mathrm{~s}^{-1}(150 \mathrm{~K}), 7.7 \times 10^{-3} \mathrm{~s}^{-1}(170 \mathrm{~K}) . c \mathrm{E}_{\mathrm{FWHM}}$ are for simulations that include the Gaussian $\mathrm{E}^{\mathrm{o}}$ distribution. 
TABLE III. ${ }^{a}$ Best Fits to Calculated Tafel Plots Derived from a Gaussian Distribution of $E^{0}$,

\begin{tabular}{|c|c|c|c|c|c|c|c|}
\hline $\begin{array}{l}\text { Charge } \\
\text { Segment }\end{array}$ & $\begin{array}{l}\lambda \\
(\mathrm{eV})\end{array}$ & $\begin{array}{l}\mu \rho\left(\mathrm{eV}^{-1} \mathrm{~s}^{-}\right. \\
\left.{ }^{1}\right) \\
\mathrm{x} 10^{-4}\end{array}$ & $\begin{array}{l}\mathrm{k}^{0}\left(\mathrm{~s}^{-1}\right) \\
\mathrm{x} 10^{3}\end{array}$ & $\begin{array}{l}\text { Charge } \\
\text { Segmen } \\
\mathfrak{t}^{c}\end{array}$ & $\begin{array}{l}\lambda \\
(\mathrm{eV})\end{array}$ & $\begin{array}{l}\mu \rho\left(\mathrm{eV}^{-1} \mathrm{~s}^{-}\right. \\
\left.{ }^{1}\right) \\
\mathrm{x} 10^{-4}\end{array}$ & $\begin{array}{l}\mathrm{k}^{0}\left(\mathrm{~s}^{-}\right. \\
\left.{ }^{1}\right) \\
\mathrm{x} 10^{3}\end{array}$ \\
\hline 1 & 0.55 & 5.4 & 5 & 1 & 0.50 & 5.1 & 1.5 \\
\hline 2 & 0.60 & 8.6 & 3.5 & 2 & 0.55 & 5.95 & 5.5 \\
\hline 3 & 0.63 & 10.3 & 1.5 & 3 & 0.61 & 9.53 & 2.2 \\
\hline 4 & 0.67 & 17.4 & 1 & 4 & 0.65 & 13.1 & 1.2 \\
\hline 5 & 0.68 & 15.3 & 0.7 & 5 & 0.67 & 13 & 0.75 \\
\hline 6 & 0.70 & 15.7 & 0.45 & 6 & 0.69 & 11.1 & 0.4 \\
\hline 7 & 0.72 & 18.8 & 0.34 & 7 & 0.71 & 11 & 0.25 \\
\hline $\begin{array}{l}\text { No } \\
\text { Dist. }\end{array}$ & 0.8 & 100 & 0.28 & $\begin{array}{l}\text { No } \\
\text { Dist. }\end{array}$ & 0.8 & 100 & 0.28 \\
\hline $\begin{array}{l}\text { Charge } \\
\text { Segment }\end{array}$ & $\begin{array}{l}\lambda \\
(\mathrm{eV})\end{array}$ & $\begin{array}{l}\mu \rho\left(\mathrm{eV}^{-1} \mathrm{~s}^{-}\right. \\
\left.{ }^{1}\right) \\
\mathrm{x} 10^{-4}\end{array}$ & $\begin{array}{l}k^{0}\left(s^{-1}\right) \\
\times 10^{2}\end{array}$ & & & & \\
\hline 1 & 0.55 & 4.3 & 4 & & & & \\
\hline 2 & 0.57 & 4.8 & 3 & & & & \\
\hline 3 & 0.63 & 10.1 & 2 & & & & \\
\hline 4 & 0.66 & 14.4 & 1.6 & & & & \\
\hline 5 & 0.71 & 28.4 & 1.2 & & & & \\
\hline 6 & 0.73 & 34.8 & 1 & & & & \\
\hline 7 & 0.75 & 38.3 & 0.75 & & & & \\
\hline $\begin{array}{l}\text { No } \\
\text { Dist. }\end{array}$ & 0.80 & 100 & 0.7 & & & & \\
\hline
\end{tabular}

'Best fit to simulations with Equation 2. Total charge divided into 10 equally sized segments. All current-time transients simulated to generate the values in the table were determined with Equation 2, 4, and 5 with $\lambda=0.80 \mathrm{eV}$ and $\mu \rho=1.0 \mathrm{x}$ $10^{6} \mathrm{eV}^{-1} \mathrm{~s}^{-1}$.

${ }^{\mathrm{b}} \mathrm{T}=125 \mathrm{~K}, \sigma\left(\mathrm{E}^{0}\right)=45 \mathrm{mV}$

${ }^{\mathrm{C}} \mathrm{T}=125 \mathrm{~K}, \sigma\left(\mathrm{E}^{0}\right)=60 \mathrm{mV}$

${ }^{\mathrm{d}} \mathrm{T}=150 \mathrm{~K}, \sigma\left(\mathrm{E}^{0,}\right)=35 \mathrm{mV}$ 
TABLE IV. ${ }^{a}$ Best Fit Kinetic Parameters to Tafel Plots Derived from a Gaussian Distribution of Redox Probe Distances

\begin{tabular}{||l|l|l|l||}
\hline Segment & $\begin{array}{l}\mu \rho\left(\mathrm{eV}^{-1} \mathrm{~s}^{-1}\right) \\
\mathrm{x} 10^{-6}\end{array}$ & $\lambda(\mathrm{eV})$ & $\begin{array}{l}\mathrm{k}^{0}\left(\mathrm{~s}^{-1}\right) \\
\mathrm{x} 10^{3}\end{array}$ \\
\hline 1 & 9.4 & 0.75 & 8.5 \\
\hline 2 & 4.4 & 0.75 & 4 \\
\hline 3 & 5.1 & 0.78 & 2.3 \\
\hline 4 & 3.5 & 0.78 & 1.6 \\
\hline 5 & 2.5 & 0.78 & 1.1 \\
\hline 6 & 1.6 & 0.78 & 0.7 \\
\hline 7 & 1 & 0.78 & 0.45 \\
\hline 8 & 0.56 & 0.78 & 0.25 \\
\hline $\begin{array}{l}\text { No } \\
\text { Distribution }\end{array}$ & 6 & 0.80 & 1.7 \\
\hline
\end{tabular}

${ }^{a}$ Best fit to simulations with Equation 2. Total charge divided into 10 equally sized segments. All current-time transients simulated to generate the values in the table were determined with Equations $2,4,5$ and 7 with $\sigma(\mathrm{d})=1.54 \AA, \lambda=0.80 \mathrm{eV}, \mu \rho_{\text {ave }}=6.0 \times 10^{6} \mathrm{eV}^{-1} \mathrm{~s}^{-1}, \mathrm{~T}=125 \mathrm{~K}, \beta=1.08 \AA^{-1}$, and $\mathrm{d}_{\text {ave }}=14 \AA$. 


\section{FIGURE LEGENDS}

Figure 1. Cyclic voltammetry of a $\mathrm{CpFeCpCO}\left(\mathrm{CH}_{2}\right)_{12} \mathrm{SH} / \mathrm{CH}_{3}\left(\mathrm{CH}_{2}\right)_{11} \mathrm{SH}$ mixed monolayer on $2.0 \times 10^{-3} \mathrm{~cm}^{2}$ polycrystalline gold in $2: 1 \mathrm{EtCl}: \operatorname{PrCN}$ with $0.075 \mathrm{M} \mathrm{Bu}_{4} \mathrm{NPF}_{6}$ (prepared from a 3:1 $\mathrm{CH}_{3}\left(\mathrm{CH}_{2}\right)_{11} \mathrm{SH} / \mathrm{CpFeCpCO}\left(\mathrm{CH}_{2}\right)_{12} \mathrm{SH}$ ethanolic solution at $1 \mathrm{mM}$ total thiol concentration). $\Gamma_{\mathrm{Fc}}$ $=1.3 \times 10^{-10} \mathrm{~mol} / \mathrm{cm}^{2}$.

Figure 2. Cyclic voltammogram (anodic wave only) from Figure 1 (open circles), and a calculated voltammogram (open squares, using Equations 2 and 4 with an $\mathrm{E}^{0}$, distribution of $\sigma\left(\mathrm{E}^{0}\right)=55 \mathrm{mV}, \mathrm{k}_{\mathrm{MPA}}=1.78 \times 10^{-4}, \mu \rho_{\mathrm{MPA}}=1.48 \times 10^{5} \mathrm{eV}^{-1} \mathrm{~s}^{-1}, \lambda=0.80 \mathrm{eV}, \nu=10 \mathrm{mV} / \mathrm{s}, \mathrm{T}$ $=135 \mathrm{~K}, \Gamma_{\mathrm{R}}{ }^{*}=1.3 \times 10^{-10} \mathrm{~mol} / \mathrm{cm}^{2} ; 21$ separate voltammograms were scaled by the Gaussian function and added together to generate a smooth simulated voltammogram.)

Currents are normalized to $i_{p}$.

Figure 3. $\log [i] \underline{v s}$. time plots generated from simulated potential step experiments with several distributions of $\mathrm{E}^{0}$, values (e.g. $\sigma\left(\mathrm{E}^{0}\right)$ ) following Equations 4 and 5. The potential step $\eta$ is equal to the average $E^{0}$ minus the applied potential. The rates for each transient were calculated from Equation 2 with $\lambda=0.80 \mathrm{eV}$ and $\mu \rho=1.0 \times 10^{6} \mathrm{eV}^{-1} \mathrm{~s}^{-1}$. The quantity of ferrocene consumed in the reaction is $\Gamma_{\mathrm{Fc}}=1.3 \times 10^{-10} \mathrm{~mol} / \mathrm{cm}^{2}$. (A) $\eta=0.0 \mathrm{~V}$ at $\mathrm{T}=125 \mathrm{~K}$, Curves A$\mathrm{E}$ are $\sigma\left(\mathrm{E}^{0}\right)=100,80,60,40,0 \mathrm{mV}$. (B) $\eta=0.25 \mathrm{~V}$ at $\mathrm{T}=125 \mathrm{~K}$, Curves A-D are $\sigma\left(\mathrm{E}^{0}\right)=100,60,40,0 \mathrm{mV}$.

Figure 4. (A) Experimental current time transient at $\mathrm{T}=125 \mathrm{~K}$ and $\eta=0.20 \mathrm{~V}$ for a $\mathrm{CpFeCpCO} 2\left(\mathrm{CH}_{2}\right)_{12} \mathrm{SH} / \mathrm{CH}_{3}\left(\mathrm{CH}_{2}\right)_{11} \mathrm{SH}$ mixed monolayer on polycrystalline gold in 2:1 EtCl:PrCN with 0.075 $\underline{\mathrm{M}} \mathrm{Bu}_{4} \mathrm{NPF}_{6}$ (prepared from a 3:1 $\mathrm{CH}_{3}\left(\mathrm{CH}_{2}\right)_{11}-\mathrm{SH} / \mathrm{CpFeCpCO}{ }_{2}\left(\mathrm{CH}_{2}\right)_{12} \mathrm{SH}$ ethanolic solution at $1 \mathrm{~m} \underline{\mathrm{M}}$ total thiol concentration). $7.95 \times 10^{5} \Omega$ positive feedback compensation and background current-subtracted. (B) $\log (\mathrm{i}) \underline{v s}$. time plot of the data in (A).

Figure 5. $\log \left(\mathrm{k}_{\mathrm{APP}, \eta}\right) \underline{v s .} \eta$ plots generated from calculated current time transients with an $\mathrm{E}^{0}$, 
distribution, $\sigma\left(\mathrm{E}^{0}\right)=45 \mathrm{mV}$, following Equations 2,4, and 5. $\mathrm{k}_{\mathrm{APP}, \eta}$ calculated at each overpotential with $\mathrm{T}=125 \mathrm{~K}, \lambda=0.80 \mathrm{eV}$ and $\mu \rho=1 \times 10^{6} \mathrm{eV}^{-1} \mathrm{~s}^{-1}$. The quantity of ferrocene consumed in the reaction is $\Gamma_{\mathrm{Fc}}=1.3 \times 10^{-10} \mathrm{~mol} / \mathrm{cm}^{2}$. Charge segments 1 (squares), 4 (triangles), and 7 (diamonds) correspond to $0-10,30-40,60-70 \%$ increments of reacting population. Best fits to each segment are shown as lines through the calculated rates: segment $1, \lambda=0.55 \mathrm{eV}, \mu \rho=5.41 \times 10^{4} \mathrm{eV}^{-1} \mathrm{~s}^{-1}$, and $\mathrm{k}^{0}=5.0 \times 10^{-3} \mathrm{~s}^{-1}$; segment $4, \lambda=0.67 \mathrm{eV}, \mu \rho=$ $1.74 \times 10^{5} \mathrm{eV}^{-1} \mathrm{~s}^{-1}$, and $\mathrm{k}^{0}=1.0 \times 10^{-3} \mathrm{~s}^{-1}$, and segment $7, \lambda=0.72 \mathrm{eV}, \mu \rho=1.88 \times 10^{5} \mathrm{eV}^{-1} \mathrm{~s}^{-1}$, and $\mathrm{k}^{0}=3.4 \times 10^{-4} \mathrm{~s}^{-1}$. Ideal curve, $\sigma\left(\mathrm{E}^{0}\right)=0$, shown as $(\mathrm{O})$.

Figure 6. $\log [\mathrm{i}] \underline{v s}$. time plots from calculated potential step experiments $(\eta=0.25 \mathrm{~V}$ at $\mathrm{T}=$ $125 \mathrm{~K}$ ) with a $1.54 \AA$ distribution of redox probe distances from the electrode surface, following Equations 2, 4 and 7. The rates for each transient were determined from Equation 2 with $\lambda=$ $0.80 \mathrm{eV}, \mu \rho_{\text {ave }}=6.0 \times 10^{6} \mathrm{eV}^{-1} \mathrm{~s}^{-1}, \mathrm{~d}_{\text {ave }}=14 \AA, \sigma(\mathrm{d})=1.54 \AA, \beta=1.08 \AA^{-1}$. The quantity of ferrocene consumed in the reaction is $\Gamma_{\mathrm{Fc}}=1.3 \times 10^{-10} \mathrm{~mol} / \mathrm{cm}^{2}$.

Figure 7. $\log \left(\mathrm{k}_{\mathrm{APP}, \eta}\right) \underline{v s .} \eta$ plots from current time transients calculated for a $1.54 \AA$ distribution of $\mathrm{d}$, following Equations 4 and 7 , for three charge segments. $\mathrm{k}_{\mathrm{APP}, \eta}$ calculated at each overpotential with $\mathrm{T}=125 \mathrm{~K}, \lambda=0.80 \mathrm{eV}, \mu \rho_{\text {ave }}=6.0 \times 10^{6} \mathrm{eV}^{-1} \mathrm{~s}^{-1}, \sigma(\mathrm{d})=1.54 \AA \mathrm{d}_{\mathrm{ave}}=14 \AA$, and $\beta=1.08 \AA^{-1}$. The quantity of ferrocene consumed in the reaction is $\Gamma_{\mathrm{Fc}}=1.3 \times 10^{-10}$ $\mathrm{mol} / \mathrm{cm}^{2}$. Best fits to each segment are shown as lines through the calculated rates; for segment $1, \lambda=0.75 \mathrm{eV}, \mu \rho=9.43 \times 10^{6} \mathrm{eV}^{-1} \mathrm{~s}^{-1}$, and $\mathrm{k}^{0}=8.5 \times 10^{-3} \mathrm{~s}^{-1}$; segment $4, \lambda=0.78 \mathrm{eV}, \mu \rho=$ $3.5 \times 10^{6} \mathrm{eV}^{-1} \mathrm{~s}^{-1}$, and $\mathrm{k}^{0}=1.6 \times 10^{-3} \mathrm{~s}^{-1}$; and segment $7, \lambda=0.78 \mathrm{eV}, \mu \rho=1.0 \times 10^{6} \mathrm{eV}^{-1} \mathrm{~s}^{-1}$, and $\mathrm{k}^{0}$ $=4.5 \times 10^{-4} \mathrm{~s}^{-1}$. Ideal curve, $\sigma(\mathrm{d})=0$, shown as $(\mathrm{O})$. 


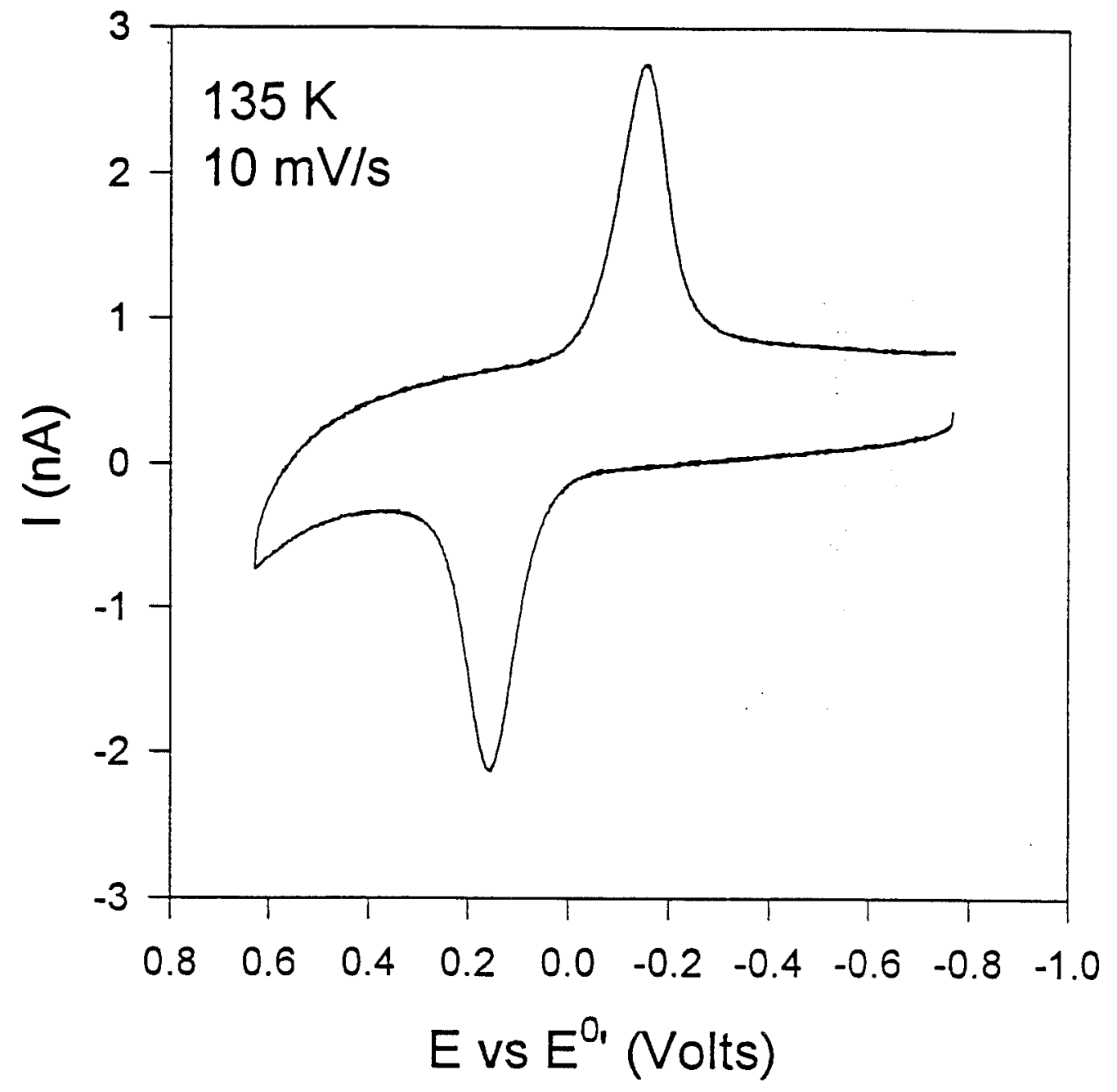




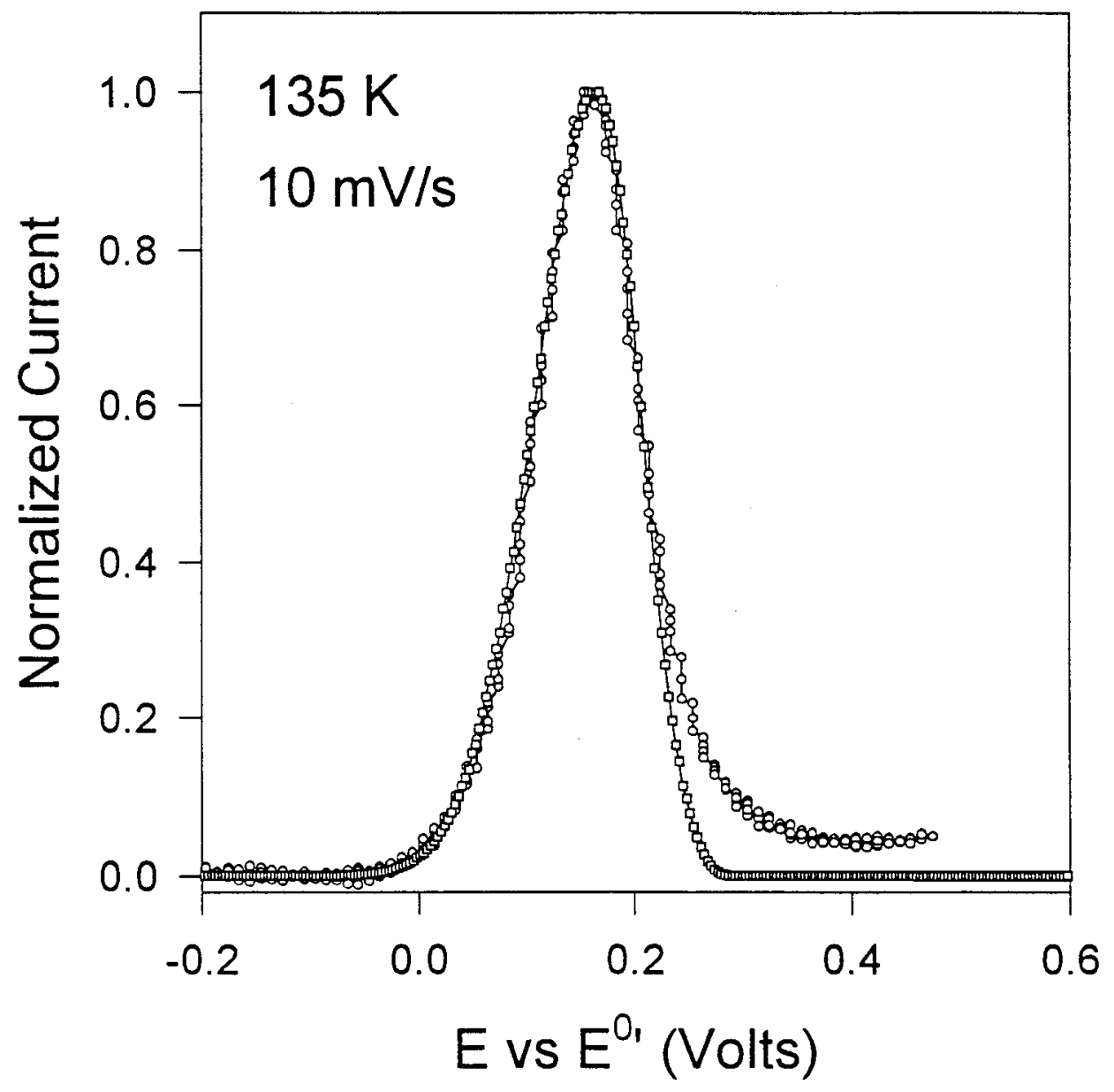




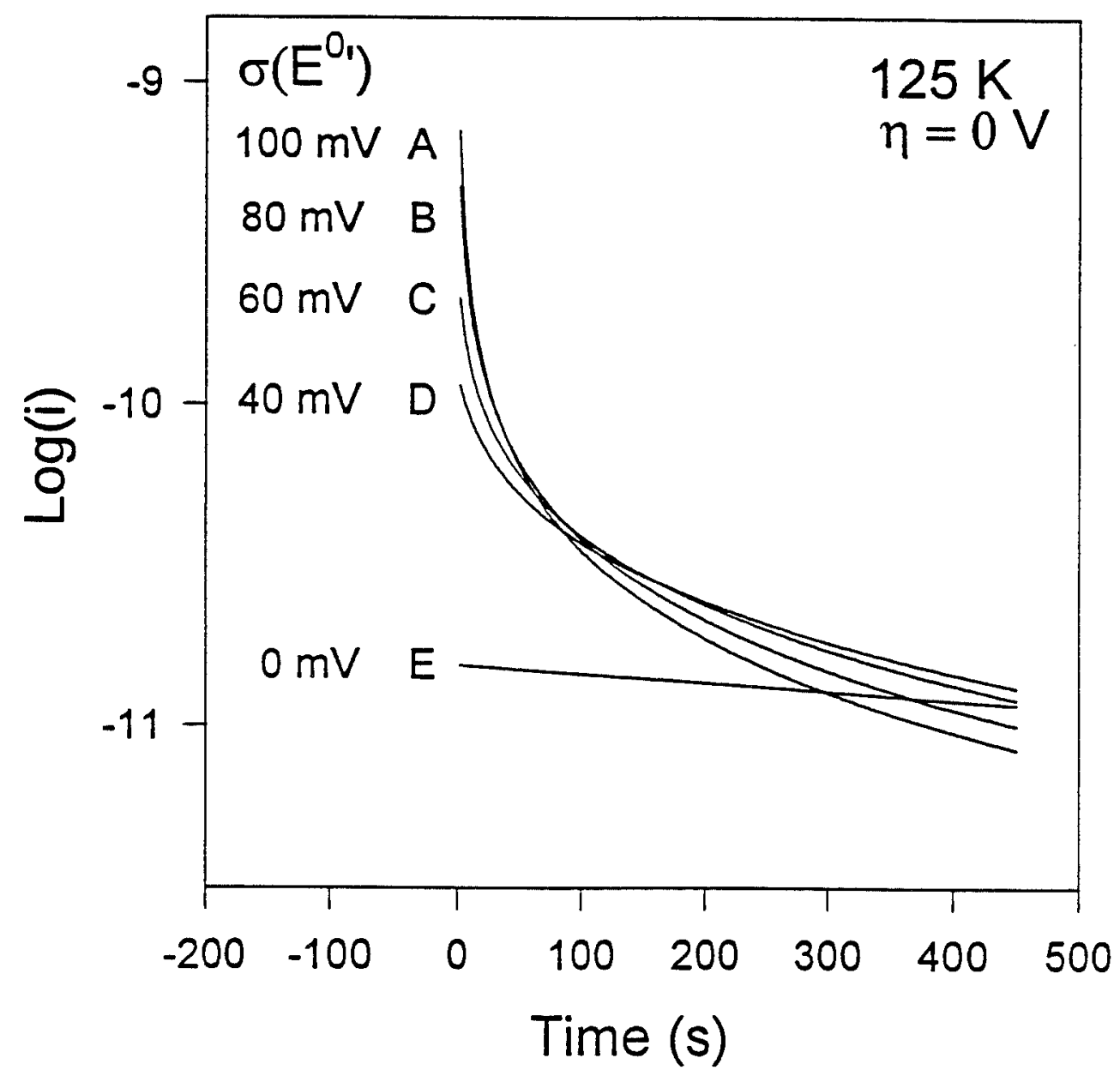




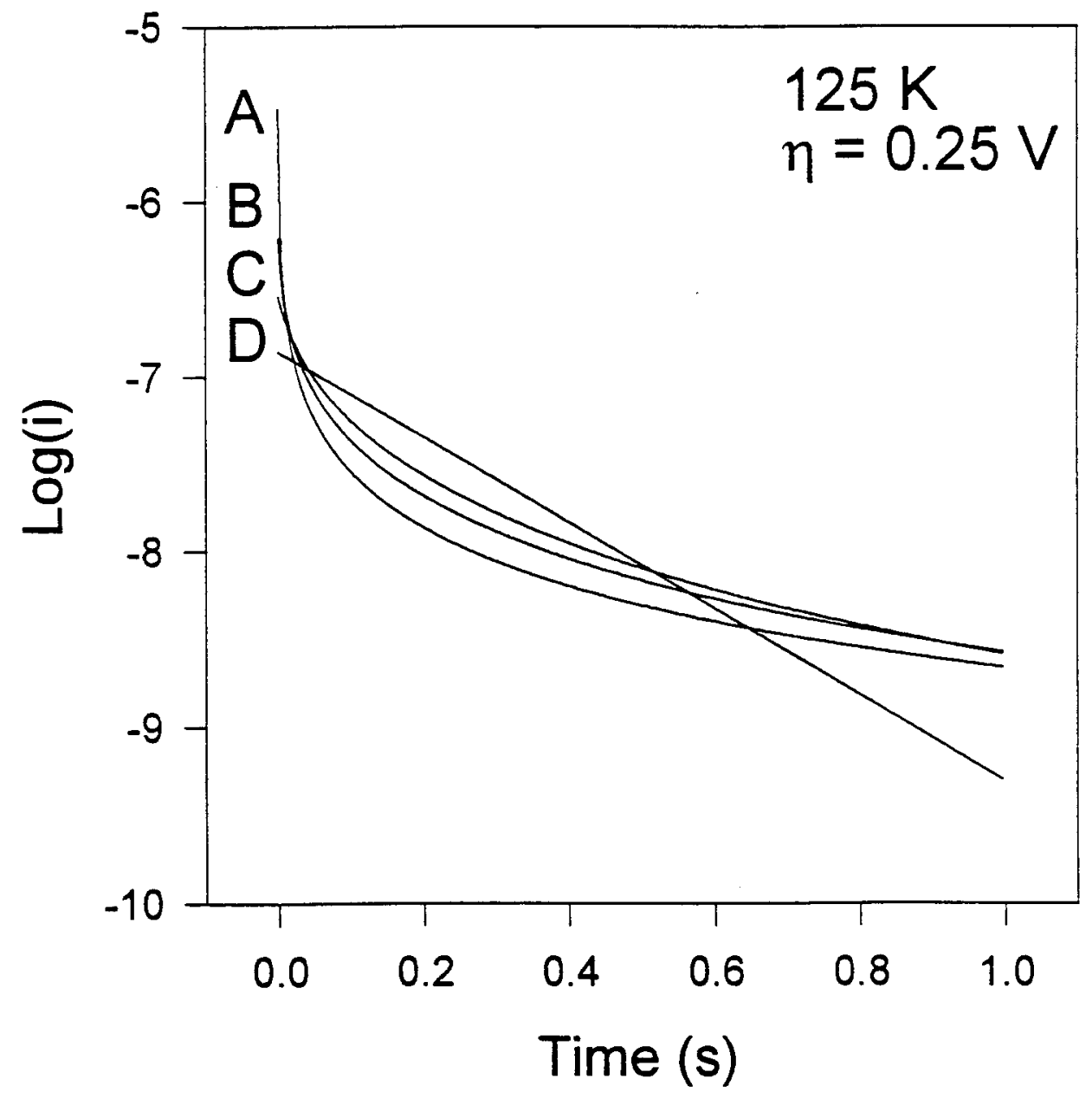



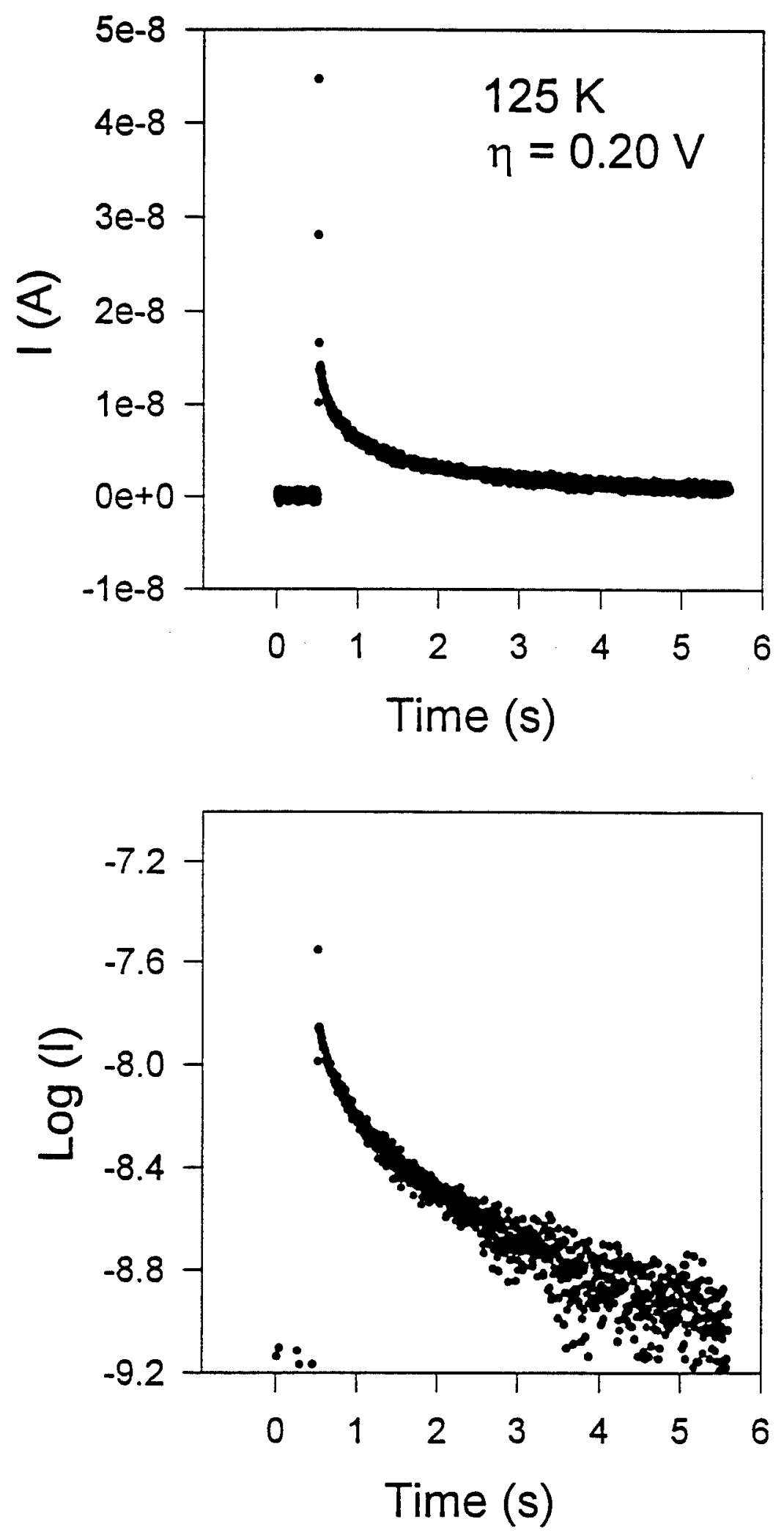


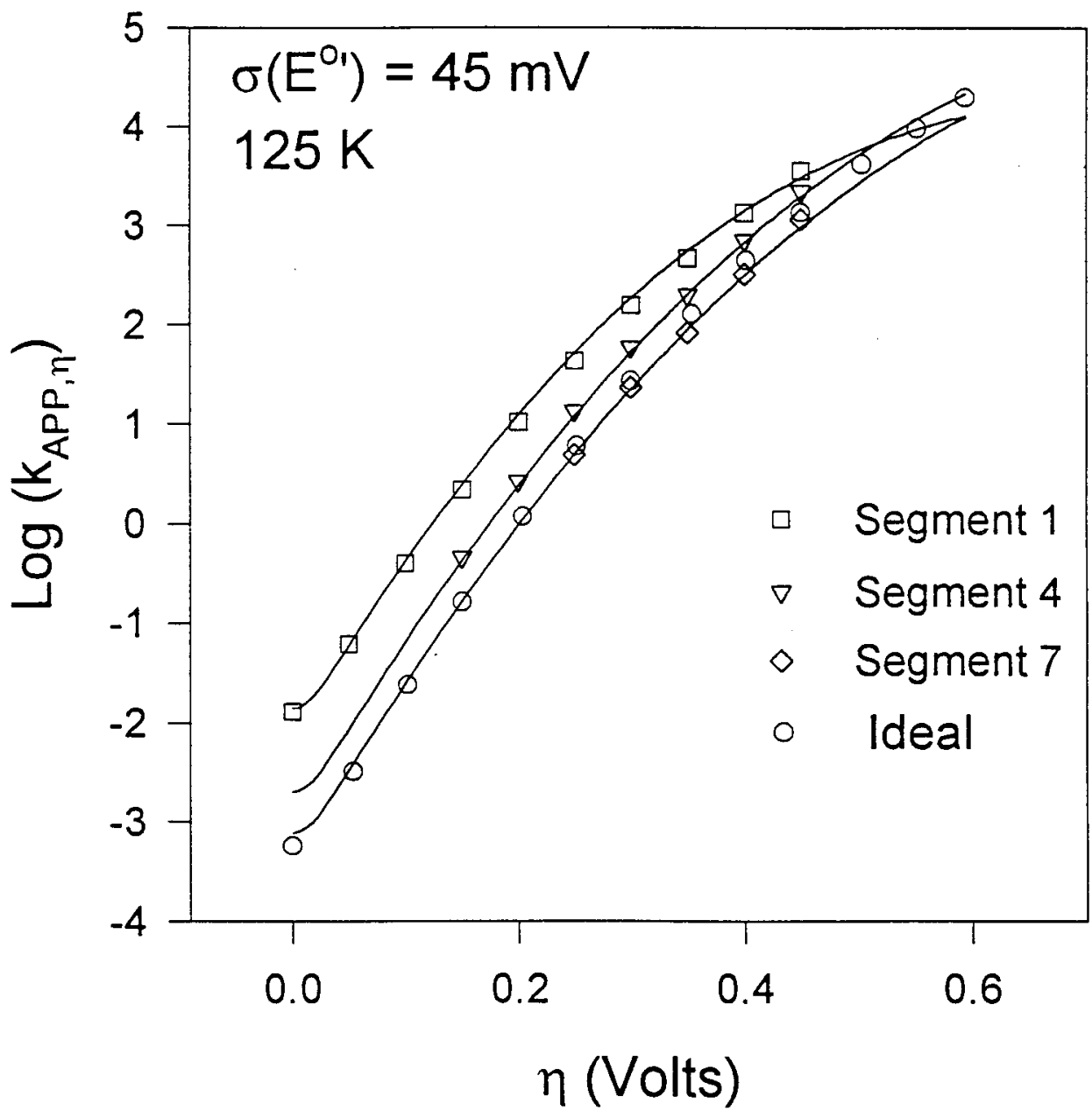




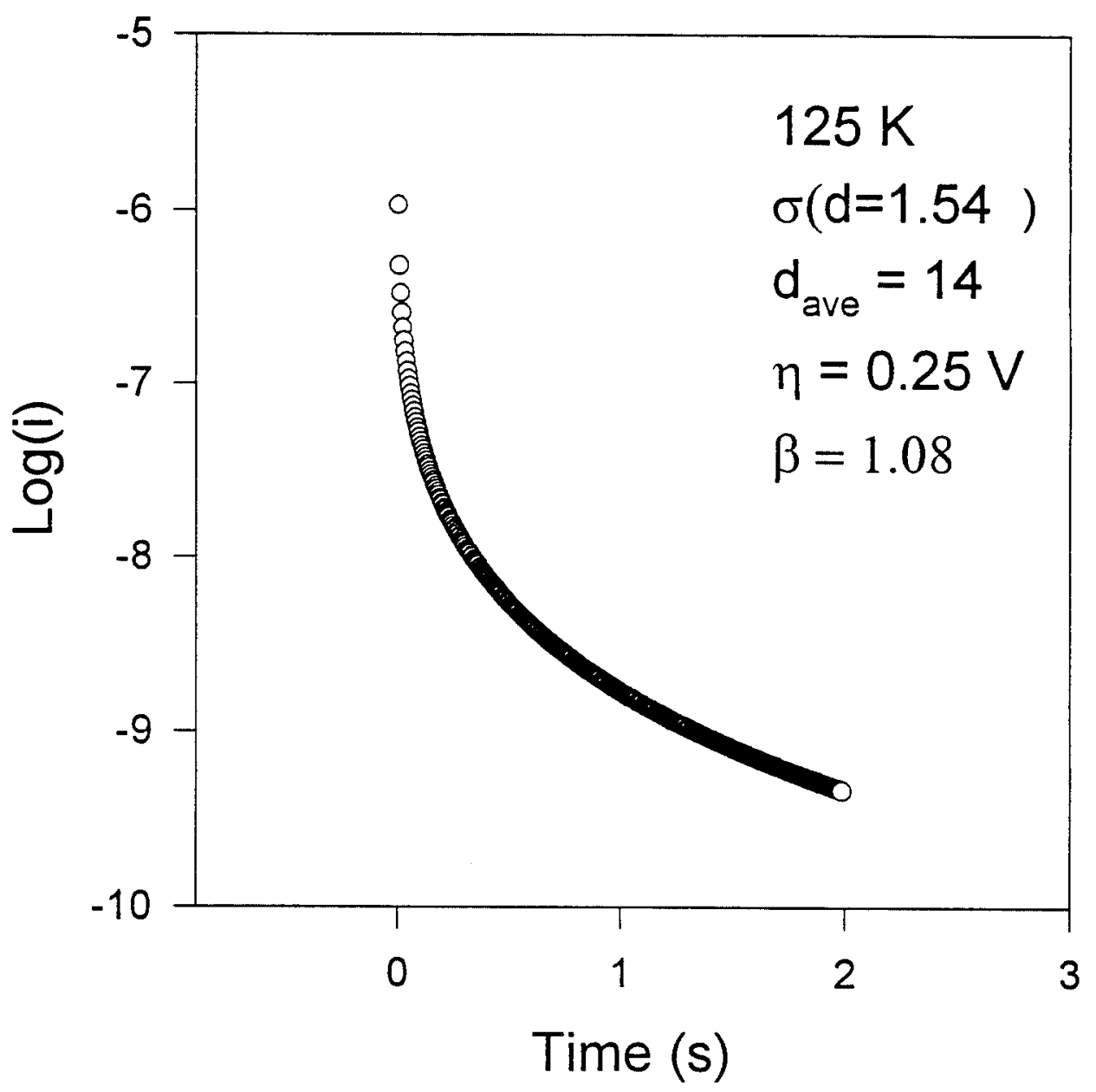




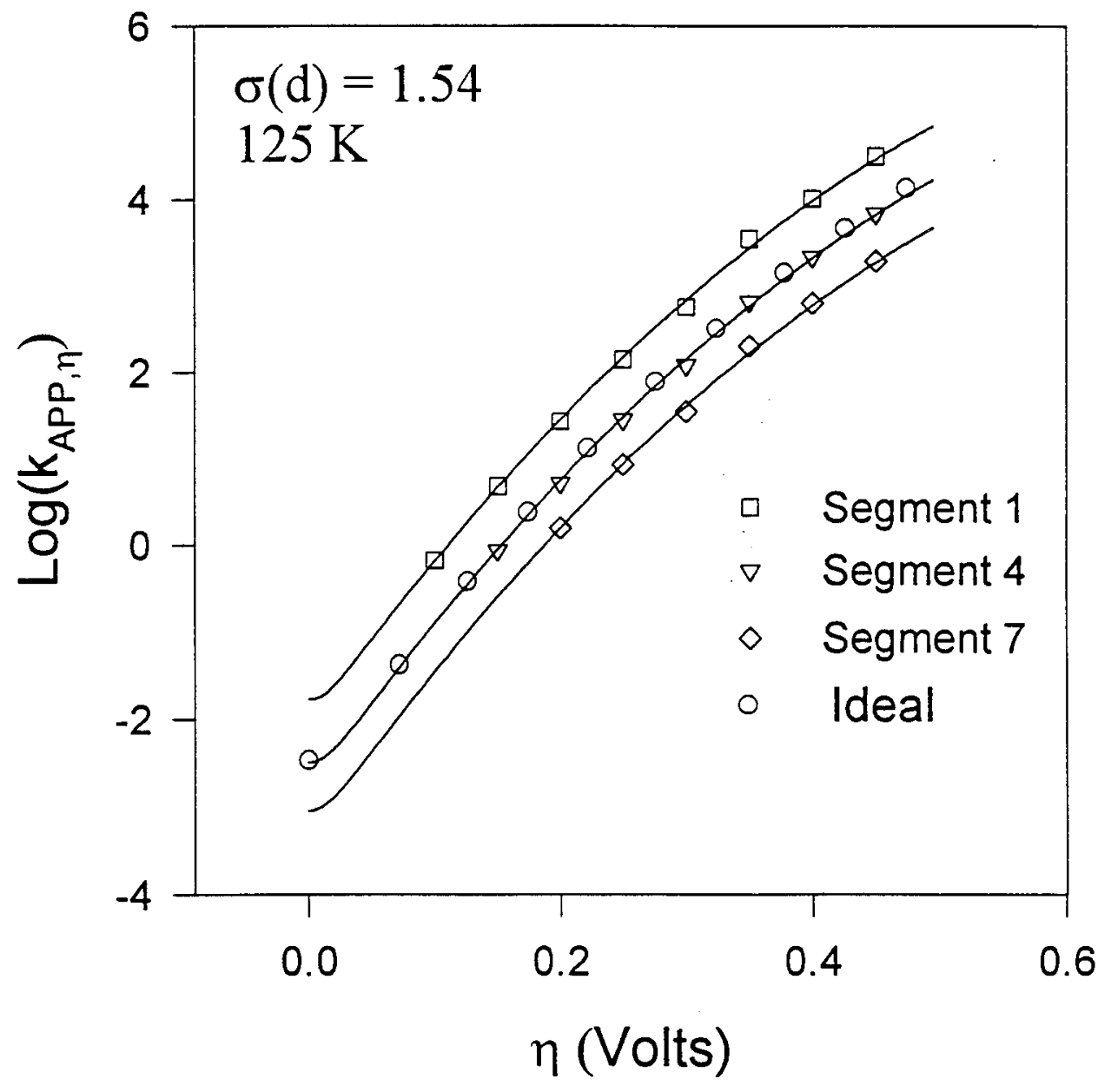

